\title{
Bioactive Compounds, Sugars, and Sensory Attributes of Organic and Conventionally Produced Courgette (Cucurbita pepo)
}

\author{
Klaudia Kopczyńska ${ }^{1, * \mathbb{D}}$, Dominika Średnicka-Tober ${ }^{1} \mathbb{D}$, Ewelina Hallmann ${ }^{1} \mathbb{D}$, Jacek Wilczak ${ }^{2} \mathbb{D}$, \\ Grażyna Wasiak-Zys ${ }^{1}$, Zdzisław Wyszyński ${ }^{3}$, Katarzyna Kucińska ${ }^{3}{ }^{\mathbb{D}}$, Aneta Perzanowska ${ }^{3}$, Paweł Szacki ${ }^{3}$, \\ Marcin Barański ${ }^{4}$ (D), Paulina Gawron ${ }^{1}$ (D), Rita Góralska-Walczak ${ }^{1}$, Ewa Rembiałkowska ${ }^{1}$ \\ and Renata Kazimierczak ${ }^{1}$ (i)
}

check for updates

Citation: Kopczyńska, K.; Średnicka-Tober, D.; Hallmann, E.; Wilczak, J.; Wasiak-Zys, G.; Wyszyński, Z.; Kucińska, K.; Perzanowska, A.; Szacki, P.; Barański, M.; et al. Bioactive Compounds, Sugars, and Sensory Attributes of Organic and Conventionally Produced Courgette (Cucurbita pepo). Foods 2021, 10, 2475. https://doi.org/ $10.3390 /$ foods 10102475

Academic Editor: Jose Galberto Martins da Costa

Received: 10 September 2021

Accepted: 13 October 2021

Published: 15 October 2021

Publisher's Note: MDPI stays neutra with regard to jurisdictional claims in published maps and institutional affiliations.

Copyright: (c) 2021 by the authors. Licensee MDPI, Basel, Switzerland. This article is an open access article distributed under the terms and conditions of the Creative Commons Attribution (CC BY) license (https:/ / creativecommons.org/licenses/by/ $4.0 /)$.
1 Department of Functional and Organic Food, Institute of Human Nutrition Sciences, Warsaw University of Life Sciences, Nowoursynowska 159c, 02-776 Warsaw, Poland; dominika_srednicka_tober@sggw.edu.pl (D.Ś.-T.); ewelina_hallmann@sggw.edu.pl (E.H.); grazyna_wasiak_zys@sggw.edu.pl (G.W.-Z.); paulina_gawron@sggw.edu.pl (P.G.); rita_goralska_walczak@sggw.edu.pl (R.G.-W.); ewa_rembialkowska@sggw.edu.pl (E.R.); renata_kazimierczak@sggw.edu.pl (R.K.)

2 Department of Physiological Sciences, Institute of Veterinary Medicine, Warsaw University of Life Sciences, Nowoursynowska 159, 02-776 Warsaw, Poland; jacek_wilczak@sggw.edu.pl

3 Department of Agronomy, Institute of Agriculture, Warsaw University of Life Science, Nowoursynowska 159, 02-787 Warsaw, Poland; zdzislaw_wyszynski@sggw.edu.pl (Z.W.); katarzyna_kucinska@sggw.edu.pl (K.K.); aneta_perzanowska@sggw.edu.pl (A.P.); pawel_szacki@sggw.edu.pl (P.S.)

4 Laboratory of Neurobiology, Nencki Institute of Experimental Biology, Polish Academy of Sciences, Pasteura 3, 02-093 Warsaw, Poland; m.baranski@nencki.edu.pl

* Correspondence: klaudia_kopczynska@sggw.edu.pl; Tel.: +48-225-937-037

\begin{abstract}
Organic agriculture is considered one of the elements of sustainable food production and consumption, mainly due to its limited impact on the natural environment. At the same time, the quality features of organically produced foods, especially sensory attributes and health promoting values, are important factors determining consumers' interest, and therefore play a key role in the organic sector's development. The aim of this study was to investigate the sensory characteristics and concentrations of sugars and selected health-promoting bioactive compounds of organic courgette compared to conventionally grown courgette. In addition, untargeted metabolomic analysis of the courgette fruits was performed. The results of this study did not show a significant effect of the horticultural system (organic vs. conventional) on the concentrations of vitamin C, carotenoids, and chlorophylls in the courgette fruits. However, the fruits from the organic systems were significantly richer in sugars when compared to the conventionally cultivated ones $(p=0.038)$. Moreover, the organic fruits fertilized with manure contained significantly higher amounts of polyphenols, including gallic acid $(p=0.016)$, chlorogenic acid $(p=0.012)$, ferulic acid $(p=0.019)$, and quercetin3-O-rutinoside $(p=0.020)$ compared to the conventional fruits. The untargeted analysis detected features significantly differentiating courgette fruits depending on the cultivar and horticultural system. Some significant differences in sensory values were also identified between fruits representing the two cultivars and coming from the horticultural systems compared in the study. Conventional courgettes were characterized by the most intensive peel color and aquosity, but at the same time were the least hard and firm compared to the fruits from the two organic systems. There was also a trend towards higher overall quality of the organically grown fruits. The presented study shows that the organic and conventional courgette fruits differ in a number of quality features which can influence consumers' health and purchasing choices.
\end{abstract}

Keywords: organic food; courgette; zucchini; Cucurbita pepo; sensory attributes; antioxidants; phenolics; sugars; untargeted metabolomic analysis; metabolic features 


\section{Introduction}

Agriculture is known to be one of the key sectors responsible for greenhouse gas emissions and climate change [1]. The orientation of agricultural development towards more environmentally friendly options is thus necessary [2-5]. These problems have been addressed in the 2030 Agenda for Sustainable Development of the United Nations, and the development of sustainable consumption and production patterns is a key target of SDG12.

Organic agriculture, as one of the extensive alternatives of industrial, intensive farming practices, is considered as a step towards more sustainable and environmentally friendly solutions, closely in line with the United Nations Environment Programme [5,6]. Organic practices are based on natural fertilizers, non-chemical plant protection methods, and diverse crop rotations $[7,8]$. Organic systems aim to minimize the impact of food production on the environment by keeping a high level of biodiversity and protecting natural resources. Although some environmental sustainability aspects of organic farming remain uncertain and are widely discussed [9], a positive impact of organic farming practices such as crop rotation on the reduction of $\mathrm{CO}_{2}$ emissions has been described in several reports [4]. Furthermore, organic systems clearly respond to the expectations of a growing number of consumers seeking food produced and processed in natural way. Thus, the market of organic foods is constantly growing [10]. This includes the market of fresh organic fruits and vegetables.

At the same time, according to the current recommendations of the World Health Organization (WHO) and the Food and Agriculture Organization of the United Nations (FAO), the recommended fruits and vegetables consumption, excluding potatoes and other starchy tubers, is a minimum of $400 \mathrm{~g}$ (or five $80 \mathrm{~g}$ portions) per day [11]. Such a portion of fruit and vegetables, abundant in fiber, vitamins, and other antioxidants and low in calories, is considered an important factor for the prevention of a number of non-communicable chronic diseases, such as cardiovascular diseases, diabetes, obesity, and certain cancers [11-14]. Increasing vegetables consumption is thus seen as one of the important steps towards a healthy diet and, if associated with a reduction in the consumption of meat, is also considered as an important change towards overall diet and food system sustainability [15].

Cucurbits (Cucurbitaceae) is a vegetable family appreciated by farmers and consumers all over the globe [16]. One of the vegetables belonging to cucurbits is courgette (Cucurbita pepo) also known as zucchini or summer squash $[16,17]$. Courgette fruits are widely used for direct consumption as well as for processing purposes $[16,18]$. Along with consumers' interest in fresh vegetables such as courgette, the demand for high-quality produce is also growing $[19,20]$. Quality features of organically produced foods, including sensory attributes and health promoting values, are important factors determining consumers' interest, and therefore play a key role in the organic sector's development. The available research on the impact of agronomic systems on the chemical composition of crops mostly shows significant differences in pesticide residue [21] and antioxidant content in organic versus conventional produce [21-26]. One of the analytical approaches increasingly used to differentiate plant raw materials and food products depending on their production and processing methods is metabolomics [27-31].

In view of the fact that the main reasons for buying organic over conventional food are their health-promoting features and higher sensory values, it seems important to conduct a chemical profile and sensory analysis of the frequently purchased vegetables, such as courgettes. The aim of this study was therefore to perform the chemical analysis and quantitative descriptive analysis (QDA) of the sensory features of organic and conventional courgette fruits of two cultivars (Nimba and Astra Polka). A targeted analysis concentrated on sugars and the determination of bioactive compounds (polyphenols, carotenoids, chlorophylls, and vitamin C). In addition, an untargeted metabolomic analysis was performed. This metabolomic analysis, without identifying specific low molecular weight compounds, was used as a supplementary tool for the targeted analysis of the qualitative features 
(sensory and chemical) in order to verify its potential for differentiating samples depending on their genotype and production system.

\section{Materials and Methods}

\subsection{Study Design and Plant Material}

In this study, fruits of two popular cultivars (Nimba and Astra Polka, Figure S1 in the Supplementary Materials) of courgette were harvested from three horticultural systems: two organic, based on (a) manure or (b) commercial organic pelleted multi-component fertilizer, and one conventional, with standard mineral fertilization. Courgettes were grown in 2018 in a controlled field trial in the Experimental Field of the Department of Agronomy, Warsaw University of Life Sciences, Miedniewice, Poland ( $51^{\circ} 57^{\prime}$ N $20^{\circ} 11^{\prime}$ E). The plots of the organic horticultural system were certified by "AGRO BIO TEST". Technologically mature courgette fruits were harvested three times in the season: at the beginning of July, at the turn of July and August, and at the end of August.

The Nimba and Astra Polka cultivars have very similar morphological features. Their fruits are characterized by an elongated and cylindrical shape which is narrow at the stem. Their skin is thin and dark green, with a fair pattern characteristic of Nimba, and light green tiny spots typical of Astra Polka.

\subsection{Preparation of Samples}

Fruits collected randomly from different locations within the field (5 $\mathrm{kg}$ from every horticultural system and cultivar combination) were delivered to the Department of Functional and Organic Food of the Warsaw University of Life Sciences. Fresh fruits were washed and cut into cubes ( 5 cubic $\mathrm{mm}$ ) from which about $20 \mathrm{~g}$ was used for the analysis of dry matter content. Another $100 \mathrm{~g}$ of fresh fruit samples were deep frozen $\left(24 \mathrm{~h},-80^{\circ} \mathrm{C}\right)$ and then freeze-dried at $-40{ }^{\circ} \mathrm{C}$ and $0.100 \mathrm{mBa}$ of pressure (Labcono 2.5 freeze-dryer, Labcono Corporation, Kansas City, MO, USA). Freeze-dried fruit samples were ground in the laboratory mill (IKA ${ }^{\circledR}$-Werke GmbH \& Co. KG, Staufen im Breisgau, Germany), placed in scintillation vials, and stored $\left(-80^{\circ} \mathrm{C}\right)$ for further analyses. This method of the preparation of samples was previously described by Średnicka-Tober et al. [32]

For the sensory analyses (quantitative descriptive analysis, QDA), around $3 \mathrm{~kg}$ of fruits from each combination of cultivar and horticultural system were washed and cut into slices of $1 \mathrm{~cm}$ of thickness and no more than $5 \mathrm{~cm}$ of diameter. Courgette slices were placed on a sieve and steamed over the boiling water for $5 \mathrm{~min}$, and then cooled at room temperature. Every QDA expert received two courgette slices from each horticultural system and cultivar.

\subsection{Chemicals}

HPLC grade acetone, ethyl acetate, and meta-phosphoric acid were obtained from Sigma-Aldrich (Poznań, Poland). HPLC grade acetonitrile, HPLC grade methanol, orthophosphoric acid, and ultrapure magnesium carbonate were obtained from Chempur (Piekary Ślaskie, Poland). Standards of $\beta$-carotene, caffeic acid, chlorogenic acid, chlorophyll $a$, chlorophyll $b$, dehydroascorbic acid, ferulic acid, gallic acid, kaempferol-3-Oglucoside, lutein, $L$-ascorbic acid, $p$-coumaric acid, and quercetin-3-O-rutinoside (HPLC grade, $99.5-99.9 \%$ pure) were obtained from Fluka and Sigma-Aldrich (Poznań, Poland). Standards of fructose (99.9\% CAS 57-48-7), glucose (99.9\% CAS 50-99-7), and sucrose $(99.9 \%$ CAS 57-50-1) were obtained from Sigma-Aldrich (Warsaw, Poland).

\subsection{Dry Matter}

The dry matter content analysis was carried out according to the Polish Norm PNEN-12145:2001 [33]. Courgette samples in cubes were weighed and hot air-dried in $105^{\circ} \mathrm{C}$ for 72 h (FP-25W Farma Play dryer, from Farma Play, Marki, Poland), and then cooled in desiccators at room temperature and weighed again. The content of dry matter was 
calculated by difference of mass before and after drying and expressed in grams in $100 \mathrm{~g}$ of fresh matter (f.w.).

\subsection{Targeted Analysis of Polyphenols-Extraction and Determination}

The content of phenolic compounds in courgette fruit samples was determined by the high performance liquid chromatography (HPLC) method, as previously described by Średnicka-Tober et al. [32]. The $100 \mathrm{mg}$ samples of courgette powder were weighed and combined with $5 \mathrm{~mL}$ of $80 \%$ methanol ( $v / v$ aqueous solution), shaken by a Micro-Shaker $326 \mathrm{M}$ (Premeo, Marki, Poland), and ultrasonicated for $10 \mathrm{~min}$ at $30^{\circ} \mathrm{C}$ and $5500 \mathrm{~Hz}$ [34]. The next step was the centrifugation of the samples for $10 \mathrm{~min}$ at $6000 \mathrm{rpm}$ and $0{ }^{\circ} \mathrm{C}$. Then, $1 \mathrm{~mL}$ of supernatant was transported into vials and analyzed by HPLC. The same HPLC system (Shimadzu, USA Manufacturing, Inc., Canby, OR, USA: two pumps LC-20AD, controller CBM-20A, column oven SIL-20AC, spectrometer UV/Vis SPD-20 AV) was used in this and all other targeted analyses described in the following sections. The volume of injection was $100 \mu \mathrm{L}$. The separation of polyphenols was conducted with the Synergi Fusion-RP 80i Phenomenex column $(250 \times 4.60 \mathrm{~mm})$ under gradient conditions with a flow rate of $1 \mathrm{~mL} \mathrm{~min}^{-1}$. The gradients of phase A and phase B were as follows: $10 \%(v / v)$ acetonitrile and ultra-pure water (phase A) and $55 \%(v / v)$ acetonitrile and ultrapure water (phase B). The ortho-phosphoric acid ( $\mathrm{pH}$ 3.0) was used for acidification. The wavelength used for detection was $270 \mathrm{~nm}$ (for phenolic acids detection) and $360 \mathrm{~nm}$ (for flavonoids detection). The external standards of polyphenols with purities of $95.00-99.99 \%$ were used for the identification of compounds. The concentrations of polyphenols were calculated based on standard curve and sample dilution coefficients.

\subsection{Targeted Analysis of Carotenoids and Chlorophylls: Extraction and Determination}

Carotenoids and chlorophylls extraction and identification was carried out as previously described by Nishiyama et al. [35], with small modifications. The freeze-dried courgette samples $(100 \mathrm{mg})$ were interfused with pure acetone $(5 \mathrm{~mL})$ and mixed by a vortex agitator. Then, samples were ultrasonicated for $15 \mathrm{~min}$ at the temperature of $0{ }^{\circ} \mathrm{C}$ and centrifuged $\left(6000 \mathrm{rpm}, 10 \mathrm{~min}, 0^{\circ} \mathrm{C}\right)$. Next, the supernatant was collected in dark glass vials. The Max-RP 80A column $(250 \times 4.6 \mathrm{~mm})$ was used for the separation of compounds. The injection volume was $100 \mu \mathrm{L}$ and detection was performed under 445 and $450 \mathrm{~nm}$ wavelengths for $18 \mathrm{~min}$. The quantification of the compounds was based on external standards.

\subsection{Targeted Analysis of Vitamin C: Extraction and Determination}

The method of vitamin C ( $L$-ascorbic acid (L-ASC) and dehydroascorbic acid (DHA)) extraction and identification was previously described in Kopczyńska et al. [36]. The dried material $(100 \mathrm{mg})$ was mixed by vortex with $5 \mathrm{~mL}$ of $5 \%$ meta-phosphoric acid. After ultrasonication $\left(15 \mathrm{~min}, 20^{\circ} \mathrm{C}\right)$ and centrifugation $\left(6000 \mathrm{rpm}, 10 \mathrm{~min}, 0^{\circ} \mathrm{C}\right)$, samples were analyzed in the HPLC device. The separation of compounds was performed with the use of a Phenomenex Hydro 80-A RP $(250 \times 4.6 \mathrm{~mm})$ column and a mobile phase of $50 \mathrm{mM}$ phosphate buffer ( $\mathrm{pH} 4.4$.) and $0.1 \mathrm{mM}$ sodium acetate. Wavelengths of 255 and $260 \mathrm{~nm}$ were used for detection. The standards of L-ASC and DHA were used for the quantification of the compounds.

\subsection{Targeted Analysis of Sugars: Extraction and Determination}

The sugars extraction and identification method used in this study was previously described by Ponder and Hallmann [37]. The freeze-dried materials (100 mg) of courgette fruits and acetone $(80 \%, 5 \mathrm{~mL})$ were mixed. Ultrasonication $\left(10 \mathrm{~min}, 0{ }^{\circ} \mathrm{C}\right)$ and centrifugation $\left(6000 \mathrm{rpm}, 10 \mathrm{~min}, 0^{\circ} \mathrm{C}\right)$ were used. The supernatant was collected and transferred to the vials. The fructose, glucose, and sucrose contents were analyzed using the HPLC system with a RID-10A detector. The fructose, glucose, and sucrose were identified and separated using a Phenomenex Luna NH2 Chromatography Column (Phenomenex, Shim- 
pol, Warsaw, Poland) under isocratic conditions with a flow rate of $1 \mathrm{~mL} \mathrm{~min}^{-1}$, using $80 \%$ acetone with deionized water. The analysis time was $15 \mathrm{~min}$. The respective sugars were identified by the analysis of the retention times of external standards.

\subsection{Quantitative Descriptive Analysis (QDA)}

The quantitative descriptive analysis (QDA) of the courgette fruits was conducted in the accredited Laboratory of Sensory Analysis in the Chair of Functional Food and Sensory Research of the Warsaw University of Life Sciences (Poland) according to ISO standard 13299:2016 [38]. The qualitative sensory attributes for the evaluation were selected by a group of experts and are presented in Table 1 . The unstructured linear scale with marked marginal values from 0 to 10 , where 0 means no intensity of a given attribute, and 10 means high intensity of a given attribute, was used in this study. The ANALSENS computer software was used for the evaluations. The analyses were performed in the laboratory with separated evaluation sites, standard lights, and controlled temperature and relative humidity. The evaluation of each sample was carried out by eight qualified experts, in two sessions, according to PN-EN ISO 8586-03:2014 [39]. The unit samples (two courgette slices each) were placed in previously prepared and coded plastic containers $(150 \mathrm{~mL})$ with lid covers. The unsweetened tea (temperature around $50^{\circ} \mathrm{C}$ ) was served to neutralize the taste between each of the evaluated samples.

Table 1. Sensory attributes used in the quantitative descriptive analysis (QDA) of organic and conventional courgette fruits of Astra Polka and Nimba cultivar.

\begin{tabular}{cccccc}
\hline \multicolumn{2}{c}{ Odor Attributes } & \multicolumn{2}{c}{ Taste Attributes } & \multicolumn{2}{c}{ Appearance and Texture Attributes and Overall Quality } \\
\hline Name & Abbreviation & Name & Abbreviation & Name & Abbreviation \\
\hline Buttery odor & bo & Potato taste & ptt & Peel color & pc \\
Potato odor & pto & Sunflower taste & sft & Flesh color & fc \\
Sweet odor & so & Buttery taste & bt & Hardness & har \\
Sunflower odor & sfo & Sweet taste & st & Firmness & fir \\
Pungent odor & pno & Cucumber taste & ct & Aquosity & aqs \\
Earthy odor & ero & Bitter taste & btt & Fibrousness & fbs \\
& & Pungent taste & pnt & Overall quality & ovq \\
\hline
\end{tabular}

\subsection{Untargeted Analysis of Metabolic Features: Extraction and Detection}

The extraction of the samples for untargeted metabolomic analysis was initiated by mixing $100 \mathrm{mg}$ of freeze-dried courgette powder by vortex with $2.5 \mathrm{~mL}$ of methanol ( $99 \%$ purity) and $2.5 \mathrm{~mL}$ of acetonitrile (99\% purity). Next, samples were centrifuged $\left(13,000 \mathrm{rpm}, 15 \mathrm{~min}, 0^{\circ} \mathrm{C}\right)$ and the supernatant was transferred into glass vials. The detection was performed using the Symbiosis Pico UHPLC system. Chromatographic separation was performed by the reversed-phase method on a Hypersil chromatographic column, BDS C18, $150 \times 4.6 \mathrm{~mm}, 5 \mathrm{~mm}$ with a Hypersil C18 guard column $(10 \times 2.1 \mathrm{~mm}$, size $5 \mu \mathrm{m})$. The mobile phase consisted of (A) methanol:formic acid (99:1, v/v) and (B) water:formic acid $(99: 1, v / v)$ and the flow rate was constant at $500 \mu \mathrm{L} \mathrm{min}^{-1}$. The gradient elution of the mobile phase started with $100 \% \mathrm{~A}$, then proceeded in the following order: 1.1-40 min, linear gradient to $100 \% \mathrm{~B} ; 40.1-55 \mathrm{~min}$, linear gradient to $100 \% \mathrm{~B}$; and 55.1-60 min, linear gradient to $100 \% \mathrm{~A}$. The runtime of the method was $60 \mathrm{~min}$. A SCIEX TripleTOF 5600+ DuoSpray Source for a SCIEX TripleTOF 5600+ (TurboIonSpray) detector was used. MS parameters were as follows: the optimized detection conditions included curtain gas $\left(\mathrm{N}_{2}\right)$ at $25 \mathrm{psi}$, nebulizer gas $(\mathrm{N} 2)$ at $20 \mathrm{psi}$, heater gas $\left(\mathrm{N}_{2}\right)$ at $50 \mathrm{psi}$, ion source voltage floating at $5500 \mathrm{~V}$, and source temperature at $500{ }^{\circ} \mathrm{C}$. Samples were measured with a heated electrospray ionization probe in positive ionization (H-ESI+). Every third sample analyzed using the Calibrant Delivery System (SCIEX) MS system was auto-calibrated using original calibrators (SCIEX). Metabolic feature profiles obtained in the 100-1100 Da range with 5 cps sensitivity were analyzed using SCIEX MarkerView ${ }^{\mathrm{TM}}$ and XCMSplus software. The 
generated metabolomics profiling data sets were processed by the control software of the Analyst ${ }^{\circledR}$ mass spectrometer and saved in a specific data format ( ${ }^{*}$.raw). The first step was to convert data from Excalibur-specific raw files to open format files ( ${ }^{*}$.mzXML) using MS Convertor software (MSConvert). Subsequently, metabolomics data were processed using the XCMSplus platform.

\subsection{Statistical Analyses}

The statistical analyses of the chemical composition and sensory attributes data were carried out in the $\mathrm{R}$ statistical environment [40]. The two-factor analyses of variance (ANOVA) were performed using a linear-mixed effects model, with the courgette cultivar and horticultural system as fixed effects, and field replication or assessor number as a random effect factor. This allowed the significance of the effects of the experimental factors and their interactions to be tested. The significance of the differences between the interaction means was tested using Tukey's HSD post hoc test. Before the parametric analyses, the normality of the data distribution was verified using the qqnorm function in $\mathrm{R}$. No data transformation was required. The principal component analysis (PCA) and redundancy analysis (RDA) were carried out using the "vegan" package library in R, to further explore possible differences and similarities in the chemical composition and sensory characteristics of the courgette fruits of two cultivars, grown under different horticultural management systems. Additionally, Pearson's product-moment correlation analyses were performed to identify potential linear associations between the individual sensory attributes using the 'cor' function in $\mathrm{R}$ and visualized with the use of the 'corrplot' package.

The results of the untargeted metabolomic analyses of the courgette fruits of two cultivars, grown in different horticultural systems, underwent principal component analysis (PCA) and were compared using Student's t-tests and fold change rate in MarkerView $^{\mathrm{TM}}$ software.

\section{Results and Discussion}

\subsection{Dry Matter and Sugars in Courgette Fruits}

The tested courgette fruits contained, on average, $4.29 \mathrm{~g}$ of dry matter in $100 \mathrm{~g}$ of fresh weight. The two-factor ANOVA showed no significant impact of the growing system and cultivar on the dry matter content in the fruits (Table 2). Other published research shows similar ranges of dry matter content in fruits of Cucurbita pepo [41]. However, different cultivars and morphological parts (mesocarp and epicarp) were shown to significantly differ in the dry matter content [41]. A higher amount of dry matter was found in fruits belonging to Cucurbita moschata and Cucurbita maxima [42]. Other authors confirm the high importance of plant genotype as a factor differentiating dry matter content in courgettes [43].

The content of fructose, glucose, sucrose, and the sum of these three sugars was also analyzed in the courgette fruits. The total content of all three sugars was higher in the fruits cultivated in the organic system with commercial organic fertilizer and manure than in the fruits cultivated conventionally. At the same time, the two tested courgette cultivars did not differ significantly in the sugars content (Table 2). Fructose was a major sugar in the tested fruits, with an average content of $1.85 \mathrm{~g}$ per $100 \mathrm{~g}$ f.w., whereas the average glucose and sucrose contents were $0.95 \mathrm{~g}$ and $1.00 \mathrm{~g}$ in $100 \mathrm{~g}$ f.w., respectively. When comparing the three production systems, sucrose content was highest in the fruits fertilized with manure, while glucose was highest in the fruits grown in the system with commercial organic fertilizer (Table 2). No significant interactions between the effect of the cultivar and horticultural system on the sugars content in the tested fruits were observed. Compared to the presented results, higher average sugars content was reported by other authors in the fruits of Cucurbita maxima [42], Cucurbita pepo [44,45], and Cucurbita moschata D. [46]. Other studies reported that courgette fruits also contain galactose, raffinose, stachyose, and starch. Fructose content was quantitatively dominant among all sugars in the courgette fruits, independently of the cultivar. In contrast to the presented results, cultivar was shown in other studies to have a significant effect on carbohydrates content in Cucurbita pepo [44] 
and Cucurbita moschata D. species [46]. At the same time, the studies on the carbohydrates content in plants depending on the cultivation system do not show consistent trends. Some authors have reported no significant production system effects on the content of these compounds [46], while others confirm that carbohydrates content in Cucurbita pepo was increased with the use of higher NPK conventional fertilizer doses [47]. The results of the largest published meta-analysis, comparing the composition of organic vs. conventionally produced crops and foods, confirmed, on average across various crop species, seasons, and production regions, a significantly higher content of carbohydrates and reducing sugars in organic compared to conventional crops [21].

Table 2. The main effect of, and interactions between, cultivar and horticultural system on the content of dry matter, and individual and sum of sugars (g/100 g f.w.) in courgette fruits.

\begin{tabular}{|c|c|c|c|c|c|}
\hline Factor & Dry Matter & Sugars (Sum) & Fructose & Glucose & Sucrose \\
\hline & \multicolumn{5}{|c|}{ Cultivar (CV) } \\
\hline Astra Polka (AP) & $4.42 \pm 0.17^{1}$ & $3.88 \pm 0.22$ & $1.93 \pm 0.12$ & $0.89 \pm 0.10$ & $1.05 \pm 0.10$ \\
\hline \multirow[t]{2}{*}{ Nimba (N) } & $4.16 \pm 0.20$ & $3.71 \pm 0.26$ & $1.76 \pm 0.16$ & $1.01 \pm 0.11$ & $0.93 \pm 0.10$ \\
\hline & \multicolumn{5}{|c|}{ Horticultural System (HS) } \\
\hline $\begin{array}{l}\text { Commercial organic } \\
\text { fertilizer (BIO) }\end{array}$ & $4.60 \pm 0.26$ & $4.24 \pm 0.29 \mathrm{~A}^{2}$ & $1.87 \pm 0.15$ & $1.36 \pm 0.13 \mathrm{~A}$ & $1.01 \pm 0.12 \mathrm{AB}$ \\
\hline Manure (MAN) & $4.39 \pm 0.24$ & $4.27 \pm 0.31 \mathrm{~A}$ & $2.12 \pm 0.21$ & $0.93 \pm 0.12 \mathrm{AB}$ & $1.21 \pm 0.12 \mathrm{~A}$ \\
\hline \multirow[t]{2}{*}{ Mineral (MIN) } & $3.96 \pm 0.15$ & $2.96 \pm 0.15 \mathrm{~B}$ & $1.56 \pm 0.07$ & $0.63 \pm 0.06 \mathrm{~B}$ & $0.77 \pm 0.10 \mathrm{~B}$ \\
\hline & \multicolumn{5}{|c|}{ ANOVA $p$-values } \\
\hline $\mathrm{CV}$ & 0.408 & 0.598 & 0.413 & 0.803 & 0.415 \\
\hline HS & 0.355 & 0.038 & 0.146 & 0.093 & 0.118 \\
\hline $\mathrm{CV} \times \mathrm{HS}$ & 0.942 & 0.825 & 0.997 & 0.539 & 0.945 \\
\hline
\end{tabular}

${ }^{1}$ Data are presented as means (average content from different fruit samples) $\pm \mathrm{SE} ;{ }^{2}$ Values in columns followed by different capital letters $(\mathrm{A}, \mathrm{B})$ are significantly different at the $5 \%$ level of probability (Tukey's test).

\subsection{Vitamin $C$ and Phenolics in Courgette Fruits}

The courgette fruits within this study were also tested for dehydroascorbic acid (DHA) and L-ascorbic acid (L-ASC) contents. Neither the cultivar nor the production system has shown to be a significant factor affecting the contents of these two compounds (Table 3). The average content of dehydroascorbic acid in the fruit was higher than the content of L-ascorbic acid (6.34 mg vs. $1.38 \mathrm{mg}$ in $100 \mathrm{~g}$ f.w., respectively). Courgette fruits are not considered a rich source of vitamin $\mathrm{C}$, and therefore the analysis of vitamin $\mathrm{C}$ content in courgettes is generally not common. Other authors reported higher ascorbic acid content in organic compared to conventional Cucurbita maxima D. [48] and no differences comparing organic and conventional Cucurbita moschata D. [46]. It was previously reported that organic crops tend to be generally richer in vitamin C compared to conventional crops [21], which is especially seen in the case of those commonly known to be rich in vitamin C.

Phenolic compounds content in the courgette fruits was also analyzed in this study. Overall, five phenolic acids were identified in the courgette fruits. Gallic acid was dominant (with an average content of $13.83 \mu \mathrm{g} \mathrm{g}^{-1} \mathrm{f} . \mathrm{w}$. in all tested courgette samples), followed by $p$-coumaric, chlorogenic, ferulic, and caffeic acids. The identified flavonoids included quercetin-3-O-rutinoside and kaempferol-3-O-glucoside (Table 4).

The organic courgette fruits contained higher amounts of polyphenols, including phenolic acids (sum) and flavonoids (sum), compared to the conventional fruits, but only when fertilized with manure. The organic fruits grown with commercial organic fertilizer were characterized by lower contents of phenolics, comparable with the conventional, minerally fertilized fruits (Table 3). A similar trend was true for most of the individual phenolic acids and flavonoids identified in the courgette fruits within the study (Table 4). At the same time, the ANOVA showed no significant cultivar effect on the content of the tested phenolic compounds (Tables 3 and 4). 
Table 3. The main effects of, and interactions between, cultivar and horticultural system on the content of vitamin $\mathrm{C}$ (mg/100 g f.w.) and selected groups of phenolic compounds ( $\mu \mathrm{g} / \mathrm{g}$ f.w.) in courgette fruits.

\begin{tabular}{|c|c|c|c|c|c|c|}
\hline Factor & $\begin{array}{c}\text { Vitamin C } \\
(\mathrm{DHA}+\mathrm{L}-\mathrm{Asc})\end{array}$ & DHA & L-Asc & $\begin{array}{l}\text { Polyphenols } \\
\text { (Sum) }\end{array}$ & $\begin{array}{l}\text { Phenolic Acids } \\
\text { (Sum) }\end{array}$ & $\begin{array}{l}\text { Flavonoids } \\
\text { (Sum) }\end{array}$ \\
\hline & \multicolumn{6}{|c|}{ Cultivar (CV) } \\
\hline Astra Polka (AP) & $8.02 \pm 0.72^{1}$ & $6.29 \pm 0.72$ & $1.52 \pm 0.15$ & $37.89 \pm 3.02$ & $33.47 \pm 2.86$ & $4.42 \pm 0.42$ \\
\hline \multirow[t]{2}{*}{ Nimba (N) } & $7.60 \pm 0.65$ & $6.40 \pm 0.60$ & $1.21 \pm 0.15$ & $40.89 \pm 3.53$ & $36.64 \pm 3.25$ & $4.25 \pm 0.47$ \\
\hline & \multicolumn{6}{|c|}{ Horticultural System (HS) } \\
\hline $\begin{array}{l}\text { Commercial organic } \\
\text { fertilizer (BIO) }\end{array}$ & $7.61 \pm 1.27$ & $6.08 \pm 1.28$ & $1.12 \pm 0.17$ & $34.42 \pm 2.81 \mathrm{~B}^{2}$ & $31.19 \pm 2.88 \mathrm{~B}$ & $3.24 \pm 0.41 \mathrm{~B}$ \\
\hline Manure (MAN) & $7.52 \pm 0.84$ & $6.27 \pm 0.83$ & $1.25 \pm 0.16$ & $53.83 \pm 3.89 \mathrm{~A}$ & $47.52 \pm 3.81 \mathrm{~A}$ & $6.31 \pm 0.47 \mathrm{~A}$ \\
\hline \multirow[t]{2}{*}{ Mineral (MIN) } & $8.31 \pm 0.46$ & $6.60 \pm 0.40$ & $1.71 \pm 0.19$ & $30.79 \pm 1.56 \mathrm{~B}$ & $27.03 \pm 1.36 \mathrm{~B}$ & $3.76 \pm 0.26 \mathrm{~B}$ \\
\hline & \multicolumn{6}{|c|}{ ANOVA $p$-values } \\
\hline $\mathrm{CV}$ & 0.969 & 0.828 & 0.192 & 0.489 & 0.493 & 0.753 \\
\hline HS & 0.872 & 0.925 & 0.128 & 0.086 & 0.119 & 0.025 \\
\hline $\mathrm{CV} \times \mathrm{HS}$ & 0.818 & 0.868 & 0.449 & 0.780 & 0.792 & 0.655 \\
\hline
\end{tabular}

${ }^{1}$ Data are presented as means (average content from different fruit samples) $\pm \mathrm{SE}^{2}$ Values in columns followed by different capital letters $(\mathrm{A}, \mathrm{B})$ are significantly different at the $5 \%$ level of probability (Tukey's test).

Table 4. The main effect of, and interactions between, cultivar and horticultural system on the content of individual phenolic acids and flavonoids ( $\mu \mathrm{g} / \mathrm{g}$ f.w.) in courgette fruits.

\begin{tabular}{|c|c|c|c|c|c|c|c|}
\hline Factor & $\begin{array}{l}\text { Gallic } \\
\text { Acid }\end{array}$ & $\begin{array}{l}\text { Chlorogenic } \\
\text { Acid }\end{array}$ & $\begin{array}{l}\text { Caffeic } \\
\text { Acid }\end{array}$ & $\begin{array}{c}p \text {-Coumaric } \\
\text { Acid }\end{array}$ & $\begin{array}{l}\text { Ferulic } \\
\text { Acid }\end{array}$ & $\begin{array}{l}\text { Quercetin-3- } \\
\text { O-rutinoside }\end{array}$ & $\begin{array}{c}\text { Kaempferol-3- } \\
\text { O-glucoside }\end{array}$ \\
\hline & \multicolumn{7}{|c|}{ Cultivar (CV) } \\
\hline Astra Polka (AP) & $13.52 \pm 1.17^{1}$ & $5.23 \pm 0.59$ & $2.99 \pm 0.61$ & $6.51 \pm 0.61$ & $3.51 \pm 0.55$ & $2.24 \pm 0.26$ & $2.18 \pm 0.27$ \\
\hline \multirow[t]{2}{*}{ Nimba $(\mathrm{N})$} & $14.20 \pm 1.37$ & $5.79 \pm 0.73$ & $3.69 \pm 0.79$ & $6.49 \pm 0.70$ & $4.22 \pm 0.55$ & $2.09 \pm 0.26$ & $2.16 \pm 0.27$ \\
\hline & \multicolumn{7}{|c|}{ Horticultural System (HS) } \\
\hline $\begin{array}{l}\text { Commercial organic } \\
\text { fertilizer (BIO) }\end{array}$ & $13.09 \pm 1.26 \mathrm{~B}^{2}$ & $3.43 \pm 0.48 \mathrm{~B}$ & $2.42 \pm 0.79$ & $7.31 \pm 0.94$ & $2.43 \pm 0.41 \mathrm{~B}$ & $1.22 \pm 0.18 \mathrm{~B}$ & $2.01 \pm 0.31 \mathrm{~B}$ \\
\hline Manure (MAN) & $18.59 \pm 1.55 \mathrm{~A}$ & $8.68 \pm 0.73 \mathrm{~A}$ & $4.81 \pm 0.98$ & $7.70 \pm 0.76$ & $6.42 \pm 0.67 \mathrm{~A}$ & $3.10 \pm 0.31 \mathrm{~A}$ & $3.22 \pm 0.25 \mathrm{~A}$ \\
\hline \multirow[t]{2}{*}{ Mineral (MIN) } & $9.71 \pm 0.81 \mathrm{~B}$ & $4.10 \pm 0.41 \mathrm{~B}$ & $2.94 \pm 0.63$ & $4.63 \pm 0.48$ & $3.02 \pm 0.30 \mathrm{~B}$ & $2.43 \pm 0.19 \mathrm{~A}$ & $1.33 \pm 0.13 \mathrm{~B}$ \\
\hline & \multicolumn{7}{|c|}{ ANOVA $p$-values } \\
\hline $\mathrm{CV}$ & 0.656 & 0.275 & 0.537 & 0.863 & 0.283 & 0.624 & 0.942 \\
\hline HS & 0.016 & 0.012 & 0.309 & 0.572 & 0.019 & 0.020 & 0.093 \\
\hline $\mathrm{CV} \times \mathrm{HS}$ & 0.243 & 0.987 & 0.771 & 0.771 & 0.406 & 0.505 & 0.781 \\
\hline
\end{tabular}

${ }^{1}$ Data are presented as means (average content from different fruit samples) $\pm \mathrm{SE} ;{ }^{2}$ Values in columns followed by different capital letters $(\mathrm{A}, \mathrm{B})$ are significantly different at the $5 \%$ level of probability (Tukey's test).

The impact of the growing system on cucurbits cultivation and quality features such as phenolics concentration were previously analyzed by some authors. Organic courgette fruits were shown to contain higher amounts of phenolic acids [49] and flavonoids $[36,50]$ compared to conventional fruits, which is generally in line with the currently obtained data.

Nitrogen availability to plants as well as irradiation were reported to be strong agronomic and environmental drivers for polyphenols concentration in recent studies comparing the effect of organic and mineral fertilizers on phenolic levels in wheat [51,52]. However, in the study reported here, the nitrogen availability pattern was not monitored, and it was therefore impossible to investigate the relation between this potential driver and phenolic levels. Previous studies with grapes, wheat, and potatoes also indicated that variety choice is a major explanatory variable for phenolics concentrations [22,53,54]. Diseases and pests pressure during plant cultivation can also result in an increase of phenolics concentrations, since these plant secondary metabolites are known to be involved in the plants' inducible response against such biotrophic stress factors [55]. Higher pest and disease incidence has been previously described as one of the main reasons for higher levels of resistance 
to phytochemicals contents in organic compared to conventional plant crops [56], even though there is no experimental evidence [51,52].

Concentrations of polyphenols in fruits of Cucurbita pepo and Cucurbita moschata are generally low compared to those found in Cucurbita maxima [17,57]. Bitter melon, which belongs to cucurbits, better known in tropical regions, is also more abundant in polyphenols compared to courgettes [58]. The variability in the contents of polyphenols in cucurbits of different genotypes, including courgettes, was previously reported [17,49,59].

\subsection{Carotenoids and Chlorophylls in Courgette Fruits}

The content of $\beta$-carotene, lutein, and zeaxanthin in courgette fruits was analyzed within this study. Neither the cultivation system nor genotype (cultivar) showed a significant effect on the concentration of these carotenoids in the courgette fruits (Table 5). $\beta$ carotene was found to be a dominant carotenoid in the tested fruits. Different species within the Cucurbitaceae family are characterized by various profiles and contents of carotenoid compounds, many of them much higher than those found in the tested courgettes $[17,46,57]$. High carotenoids concentrations are especially typical for orange pulp cucurbits [59]. In contrast to the presented results, many studies also reported significant differences in the carotenoids content depending on the cultivar of particular species $[17,41,60]$. When comparing crops from different agronomic systems, higher quantities of carotenoids were found, on average, in organic compared to conventional crops [21,61], including pumpkin [48].

Table 5. The main effect of, and interaction between, cultivar and horticultural system on the content of carotenoids and chlorophylls (mg/100 g f.w.) in courgette fruits.

\begin{tabular}{|c|c|c|c|c|c|c|c|}
\hline Factor & $\begin{array}{l}\text { Carotenoids } \\
\quad \text { (Sum) }\end{array}$ & $\beta$-Carotene & Lutein & Zeaxanthin & $\begin{array}{l}\text { Chlorophylls } \\
\text { (Sum) }\end{array}$ & $\begin{array}{c}\text { Chlorophyll } \\
a\end{array}$ & $\begin{array}{c}\text { Chlorophyll } \\
b\end{array}$ \\
\hline & \multicolumn{7}{|c|}{ Cultivar (CV) } \\
\hline Astra Polka (AP) & $1.21 \pm 0.11^{1}$ & $1.10 \pm 0.11$ & $0.08 \pm 0.00$ & $0.03 \pm 0.00$ & $2.23 \pm 0.18$ & $1.71 \pm 0.16$ & $0.52 \pm 0.03$ \\
\hline \multirow[t]{2}{*}{ Nimba (N) } & $1.19 \pm 0.16$ & $1.08 \pm 0.16$ & $0.08 \pm 0.01$ & $0.03 \pm 0.00$ & $2.01 \pm 0.16$ & $1.51 \pm 0.14$ & $0.50 \pm 0.03$ \\
\hline & \multicolumn{7}{|c|}{ Horticultural system (HS) } \\
\hline $\begin{array}{l}\text { Commercial organic } \\
\text { fertilizer (BIO) }\end{array}$ & $1.17 \pm 0.14$ & $1.06 \pm 0.14$ & $0.09 \pm 0.01$ & $0.03 \pm 0.00$ & $2.21 \pm 0.22$ & $1.70 \pm 0.19$ & $0.51 \pm 0.04$ \\
\hline Manure (MAN) & $1.47 \pm 0.20$ & $1.36 \pm 0.20$ & $0.08 \pm 0.01$ & $0.03 \pm 0.00$ & $2.35 \pm 0.24$ & $1.80 \pm 0.21$ & $0.55 \pm 0.03$ \\
\hline \multirow[t]{2}{*}{ Mineral (MIN) } & $0.96 \pm 0.11$ & $0.86 \pm 0.11$ & $0.08 \pm 0.00$ & $0.03 \pm 0.00$ & $1.84 \pm 0.15$ & $1.37 \pm 0.13$ & $0.47 \pm 0.03$ \\
\hline & \multicolumn{7}{|c|}{ ANOVA $p$-values } \\
\hline $\mathrm{CV}$ & 0.950 & 0.966 & 0.479 & 0.426 & 0.461 & 0.396 & 0.744 \\
\hline HS & 0.557 & 0.568 & 0.514 & 0.443 & 0.409 & 0.313 & 0.642 \\
\hline $\mathrm{CV} \times \mathrm{HS}$ & 0.978 & 0.977 & 0.999 & 0.973 & 0.866 & 0.748 & 0.942 \\
\hline
\end{tabular}

${ }^{1}$ Data are presented as means (average content from different fruit samples) $\pm \mathrm{SE}$.

The chlorophyll (chlorophyll $a$ and chlorophyll $b$ ) contents in courgette fruits were also analyzed and, similar to carotenoids, none of the factors had a significant impact on chlorophyll $a$ and chlorophyll $b$ content (Table 5). The chlorophyll $a$ content was higher than that of chlorophyll $b(1.62 \mathrm{mg}$ vs. $0.51 \mathrm{mg}$ in $100 \mathrm{~g}$ f.w. on average in all courgette fruits, respectively). Even though chlorophylls belong to valuable antioxidants [62], their analysis in vegetables, such as courgettes, is rare. Some authors reported a significant impact of courgette cultivar on chlorophylls concentration [63]. Although it is known that the organic way of growing increases the production of many antioxidants in plants, the chlorophyll content of organic vegetables is not often discussed. Higher chlorophyll content is usually discussed as the reaction of plants to oxidative stress [64].

\subsection{Principal Component Analysis: Chemical Composition of Courgette Fruits}

A principal component analysis (PCA) was performed to further explore possible differences and similarities in the composition of the courgette fruits representing different cultivars (Figure 1a) and grown in different horticultural systems (Figure 1b). While 
the PCA ellipses based on the data for the two courgette cultivars clearly overlap each other, those of the three horticultural systems show a clearer separation. The PCA plot also shows a positive association between the horticultural system based on organic fertilization (manure) and concentrations of a majority of the tested compounds, mainly phenolics (Figure 1b). A similar association was not observed between the cultivar and fruit composition parameters when the results for the two cultivars were plotted (Figure 1a).

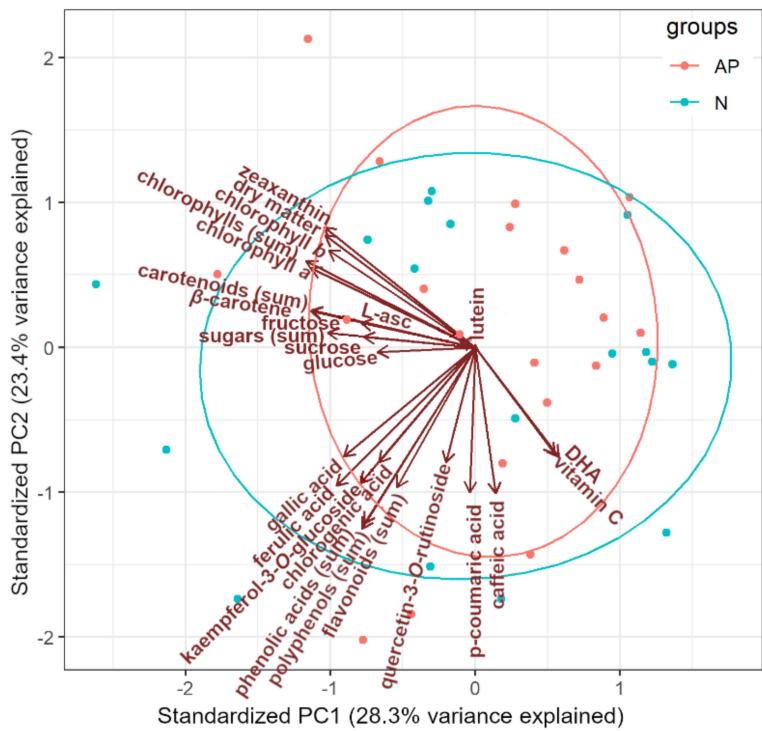

(a)

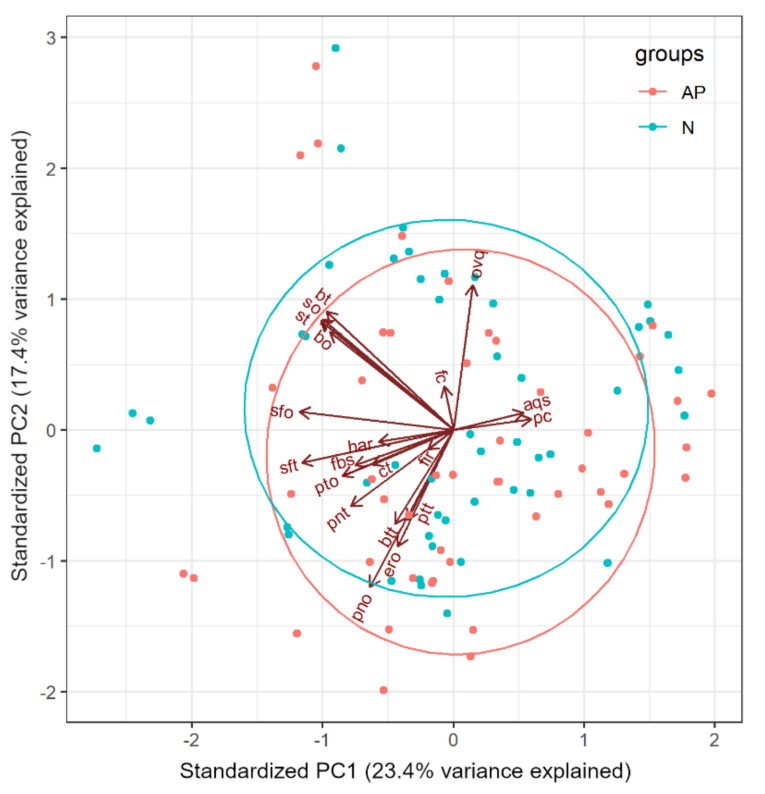

(c)

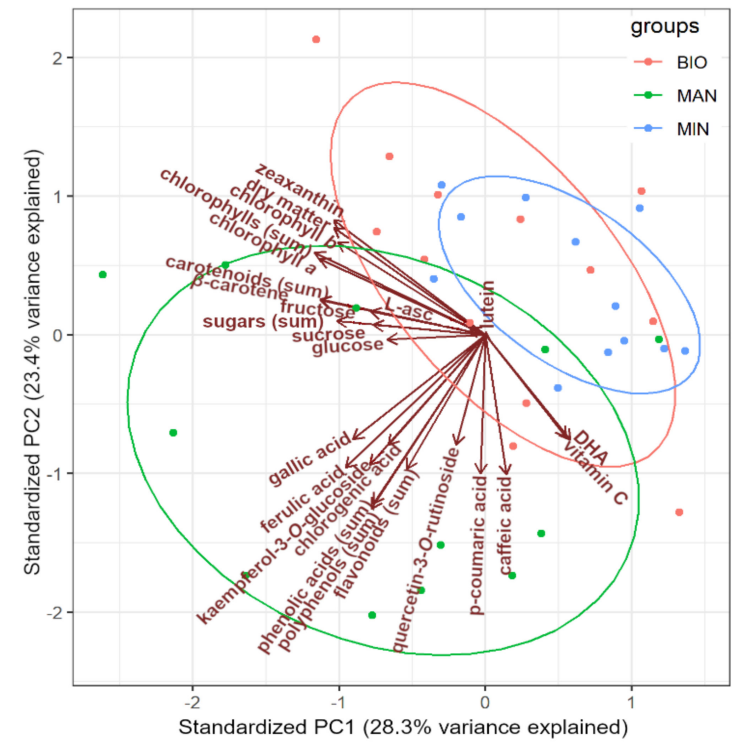

(b)

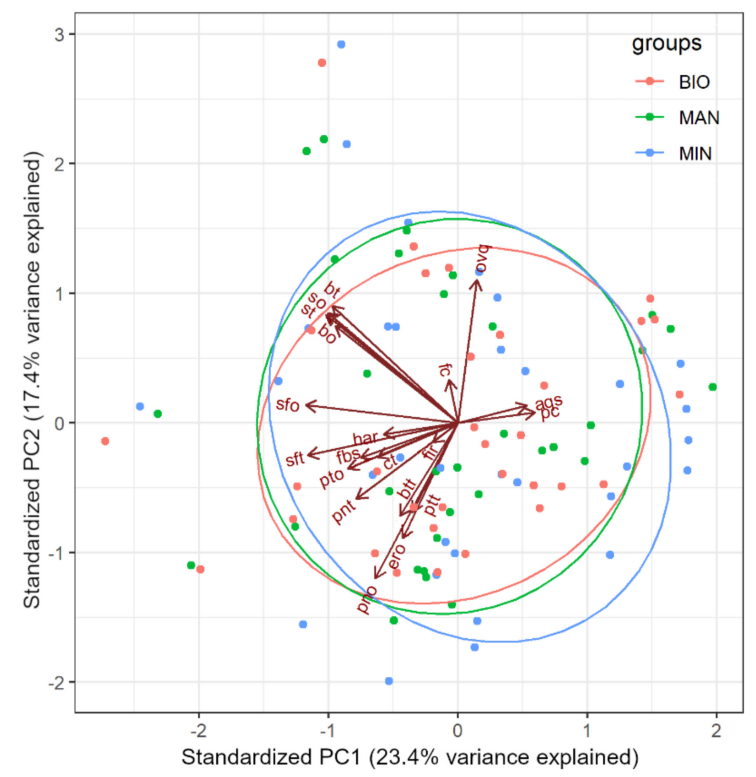

(d)

Figure 1. Principal component analysis (PCA) biplots of data on chemical composition, sugars and bioactive compounds of fruits of Astra Polka (AP) and Nimba (N) cultivars, (a) grown in horticultural system with commercial organic fertilizer (BIO), manure (MAN), and mineral (MIN) fertilizer, (b) as well as data on sensory attributes of fruits of (c) both cultivars and (d) grown with three fertilizers. PC1, the first principal component; PC2, the second principal component; Bo, buttery odor; pto, potato odor; so, sweet odor; sfo, sunflower odor; pno, pungent odor; ero, earthy odor; ptt, potato taste; sft, sunflower taste; bt, buttery taste; st, sweet taste; ct, cucumber taste; btt, bitter taste; pnt, pungent taste; pc, peel color; fc, flesh color; har, hardness; fir, firmness; aqs, aquosity; fbs, fibrousness; ovq, overall quality. 


\subsection{Sensory Features of Courgette Fruits}

Sensory features, including taste attributes, are crucial for consumers' view on foods. The evaluation of sensory attributes gives valuable information for the development of new food products and the improvement of existing ones [65]. The results of the sensory characteristics of the courgette fruits tested within the present study, including odor, taste, appearance, texture, and overall quality, are presented in Tables 6-8 and Figures 2-4 and Figures S2-S4 (in the Supplementary Materials). The horticultural system appeared to have a significant effect on the potato odor of the courgette fruits (Table 6).

Table 6. The main effect of, and interactions between, cultivar and horticultural system on the odor attributes of courgette fruits.

\begin{tabular}{|c|c|c|c|c|c|c|}
\hline Factor & $\begin{array}{l}\text { Buttery } \\
\text { Odor }\end{array}$ & $\begin{array}{l}\text { Potato } \\
\text { Odor }\end{array}$ & $\begin{array}{l}\text { Sweet } \\
\text { Odor }\end{array}$ & $\begin{array}{c}\text { Sunflower } \\
\text { Odor }\end{array}$ & $\begin{array}{l}\text { Pungent } \\
\text { Odor }\end{array}$ & $\begin{array}{l}\text { Earthy } \\
\text { Odor }\end{array}$ \\
\hline & \multicolumn{6}{|c|}{ Cultivar (CV) } \\
\hline Astra Polka (AP) & $1.70^{1} \pm 0.29$ & $2.96 \pm 0.25$ & $1.47 \pm 0.25$ & $2.04 \pm 0.22$ & $1.97 \pm 0.23 \mathrm{~A}$ & $1.74 \pm 0.27 \mathrm{~A}$ \\
\hline \multirow[t]{2}{*}{ Nimba (N) } & $1.92 \pm 0.29$ & $2.57 \pm 0.23$ & $1.82 \pm 0.27$ & $2.39 \pm 0.25$ & $1.44 \pm 0.20 \mathrm{~B}$ & $1.05 \pm 0.17 \mathrm{~B}$ \\
\hline & \multicolumn{6}{|c|}{ Horticultural system (HS) } \\
\hline $\begin{array}{l}\text { Commercial organic } \\
\text { fertilizer (BIO) }\end{array}$ & $1.73 \pm 0.31$ & $2.28 \pm 0.23 \mathrm{~B}^{2}$ & $1.55 \pm 0.26$ & $2.36 \pm 0.32$ & $1.68 \pm 0.26$ & $1.37 \pm 0.27$ \\
\hline Manure (MAN) & $1.78 \pm 0.40$ & $3.06 \pm 0.28 \mathrm{~A}$ & $1.69 \pm 0.31$ & $2.34 \pm 0.28$ & $1.67 \pm 0.27$ & $1.25 \pm 0.22$ \\
\hline \multirow[t]{2}{*}{ Mineral (MIN) } & $1.93 \pm 0.36$ & $2.95 \pm 0.33 \mathrm{AB}$ & $1.69 \pm 0.38$ & $1.94 \pm 0.28$ & $1.77 \pm 0.28$ & $1.57 \pm 0.33$ \\
\hline & \multicolumn{6}{|c|}{ ANOVA $p$-value } \\
\hline $\mathrm{CV}$ & NS & NS & NS & NS & 0.012 & 0.007 \\
\hline HS & NS & 0.021 & NS & NS & NS & NS \\
\hline $\mathrm{CV} \times \mathrm{HS}$ & $<0.001$ & $<0.001$ & NS & NS & 0.004 & $<0.001$ \\
\hline
\end{tabular}

${ }^{1}$ The numerical values given are based on a 10-point scale and are presented as means (average evaluation score of different fruit samples) $\pm \mathrm{SE} ;{ }^{2}$ Values in columns followed by different capital letters (A,B) are significantly different at the $5 \%$ level of probability (Tukey's test).

Table 7. The main effect of, and interactions between, cultivar and horticultural system on the taste attributes of courgette fruits.

\begin{tabular}{|c|c|c|c|c|c|c|c|}
\hline Factor & $\begin{array}{l}\text { Potato } \\
\text { Taste }\end{array}$ & $\begin{array}{l}\text { Sunflower } \\
\text { Taste }\end{array}$ & $\begin{array}{l}\text { Buttery } \\
\text { Taste }\end{array}$ & $\begin{array}{l}\text { Sweet } \\
\text { Taste }\end{array}$ & $\begin{array}{l}\text { Cucumber } \\
\text { Taste }\end{array}$ & $\begin{array}{l}\text { Bitter } \\
\text { Taste }\end{array}$ & $\begin{array}{l}\text { Pungent } \\
\text { Taste }\end{array}$ \\
\hline & \multicolumn{7}{|c|}{ Cultivar (CV) } \\
\hline Astra Polka (AP) & $2.97^{1} \pm 0.22$ & $2.57 \pm 0.29$ & $1.19 \pm 0.25$ & $1.63 \pm 0.27 \mathrm{~B}^{2}$ & $2.53 \pm 0.21 \mathrm{~B}$ & $1.08 \pm 0.22$ & $1.22 \pm 0.26 \mathrm{~A}$ \\
\hline \multirow[t]{2}{*}{ Nimba (N) } & $2.66 \pm 0.24$ & $2.76 \pm 0.28$ & $1.26 \pm 0.21$ & $2.03 \pm 0.30 \mathrm{~A}$ & $3.05 \pm 0.24 \mathrm{~A}$ & $0.74 \pm 0.15$ & $0.76 \pm 0.18 \mathrm{~B}$ \\
\hline & \multicolumn{7}{|c|}{ Horticultural System (HS) } \\
\hline $\begin{array}{l}\text { Commercial organic } \\
\text { fertilizer (BIO) }\end{array}$ & $2.55 \pm 0.26$ & $2.98 \pm 0.42$ & $1.05 \pm 0.26$ & $1.81 \pm 0.39$ & $3.04 \pm 0.33$ & $1.01 \pm 0.26$ & $1.01 \pm 0.28$ \\
\hline Manure (MAN) & $2.69 \pm 0.31$ & $2.68 \pm 0.32$ & $1.20 \pm 0.26$ & $1.73 \pm 0.30$ & $2.80 \pm 0.24$ & $0.71 \pm 0.19$ & $0.88 \pm 0.25$ \\
\hline \multirow[t]{2}{*}{ Mineral (MIN) } & $3.21 \pm 0.28$ & $2.35 \pm 0.31$ & $1.43 \pm 0.32$ & $1.93 \pm 0.38$ & $2.53 \pm 0.26$ & $1.02 \pm 0.24$ & $1.08 \pm 0.29$ \\
\hline & \multicolumn{7}{|c|}{ ANOVA $p$-values } \\
\hline $\mathrm{CV}$ & NS & NS & NS & 0.046 & 0.037 & NS & 0.025 \\
\hline HS & NS & NS & NS & NS & NS & NS & NS \\
\hline $\mathrm{CV} \times \mathrm{HS}$ & NS & NS & 0.043 & 0.017 & NS & NS & NS \\
\hline
\end{tabular}

${ }^{1}$ The numerical values given are based on a 10-point scale and are presented as means (average evaluation score of different fruit samples) $\pm \mathrm{SE} ;{ }^{2}$ Values in columns followed by different capital letters (A,B) are significantly different at the $5 \%$ level of probability (Tukey's test). 
Table 8. The main effect of, and interaction between, cultivar and horticultural system on the appearance and physical attributes as well as overall quality assessment of courgette fruits.

\begin{tabular}{|c|c|c|c|c|c|c|c|}
\hline Factor & Peel Color & Flesh Color & Hardness & Firmness & Aquosity & Fibrousness & $\begin{array}{l}\text { Overall } \\
\text { Quality }\end{array}$ \\
\hline & \multicolumn{7}{|c|}{ Cultivar (CV) } \\
\hline Astra Polka (AP) & $7.10^{1} \pm 0.26$ & $4.78 \pm 0.36$ & $4.06 \pm 0.33 \mathrm{~B}$ & $4.36 \pm 0.32 \mathrm{~B}$ & $5.42 \pm 0.30$ & $2.68 \pm 0.27$ & $5.36 \pm 0.22$ \\
\hline \multirow[t]{2}{*}{ Nimba $(\mathrm{N})$} & $6.45 \pm 0.34$ & $5.03 \pm 0.41$ & $5.12 \pm 0.31 \mathrm{~A}$ & $5.32 \pm 0.32 \mathrm{~A}$ & $4.95 \pm 0.27$ & $2.81 \pm 0.30$ & $5.57 \pm 0.25$ \\
\hline & \multicolumn{7}{|c|}{ Horticultural System (HS) } \\
\hline $\begin{array}{l}\text { Commercial organic } \\
\text { fertilizer (BIO) }\end{array}$ & $6.60 \pm 0.34 \mathrm{AB}^{2}$ & $4.68 \pm 0.50$ & $4.96 \pm 0.46 \mathrm{~A}$ & $5.40 \pm 0.41 \mathrm{~A}$ & $4.83 \pm 0.30 \mathrm{~B}$ & $2.88 \pm 0.37$ & $5.57 \pm 0.37$ \\
\hline Manure (MAN) & $6.34 \pm 0.47 \mathrm{~B}$ & $5.06 \pm 0.49$ & $5.06 \pm 0.36 \mathrm{~A}$ & $5.43 \pm 0.35 \mathrm{~A}$ & $4.67 \pm 0.30 \mathrm{~B}$ & $2.84 \pm 0.32$ & $5.69 \pm 0.28$ \\
\hline \multirow[t]{2}{*}{ Mineral (MIN) } & $7.38 \pm 0.28 \mathrm{~A}$ & $4.98 \pm 0.42$ & $3.75 \pm 0.35 \mathrm{~B}$ & $3.70 \pm 0.36 \mathrm{~B}$ & $6.06 \pm 0.39 \mathrm{~A}$ & $2.51 \pm 0.35$ & $5.13 \pm 0.28$ \\
\hline & \multicolumn{7}{|c|}{ ANOVA $p$-value } \\
\hline $\mathrm{CV}$ & NS & NS & 0.010 & 0.020 & NS & NS & NS \\
\hline HS & 0.035 & NS & 0.016 & $<0.001$ & $<0.001$ & NS & NS \\
\hline $\mathrm{CV} \times \mathrm{HS}$ & NS & NS & NS & NS & NS & NS & 0.031 \\
\hline
\end{tabular}

${ }^{1}$ The numerical values given are based on a 10-point scale and are presented as means (average evaluation score of different fruit samples) $\pm \mathrm{SE}{ }^{2}$ Values in columns followed by different capital letters $(\mathrm{A}, \mathrm{B})$ are significantly different at the $5 \%$ level of probability (Tukey's test).

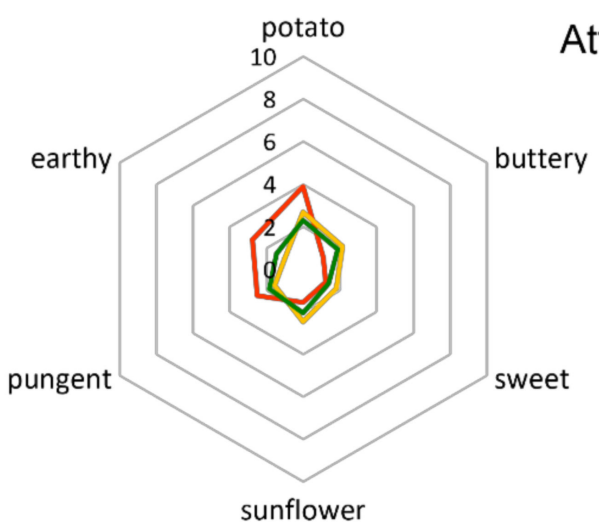

Astra Polka

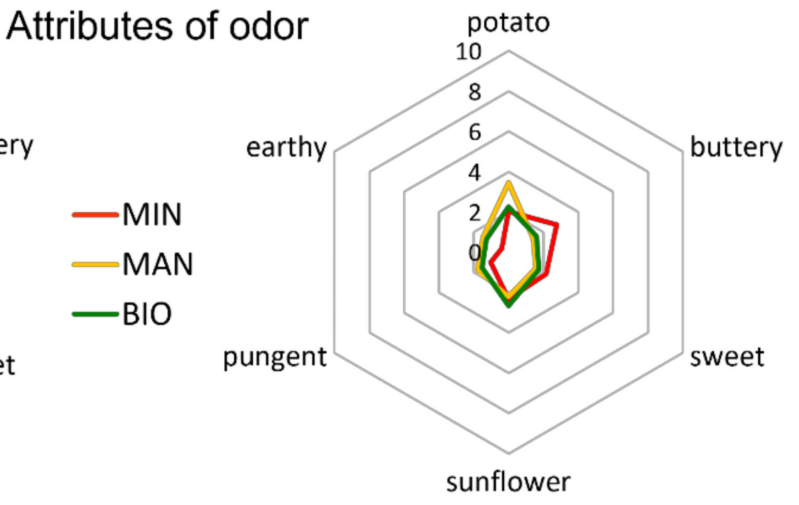

Nimba

Figure 2. Intensity of odor attributes of courgette fruits of Astra Polka and Nimba cultivars grown in horticultural system with commercial organic fertilizer (BIO), manure (MAN), and mineral (MIN) fertilizer.

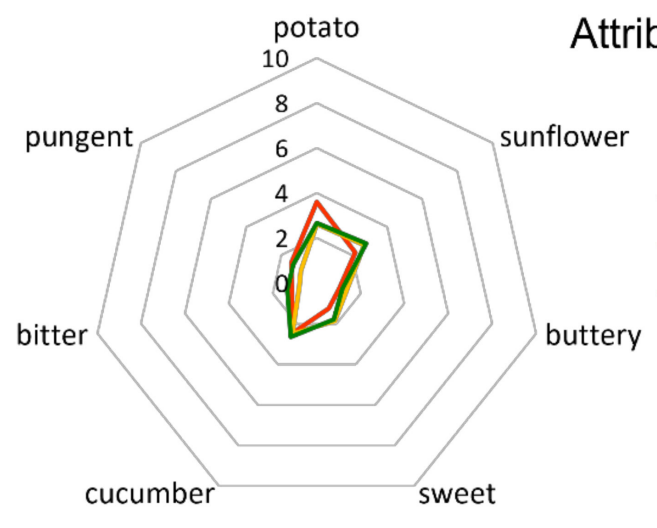

Astra Polka

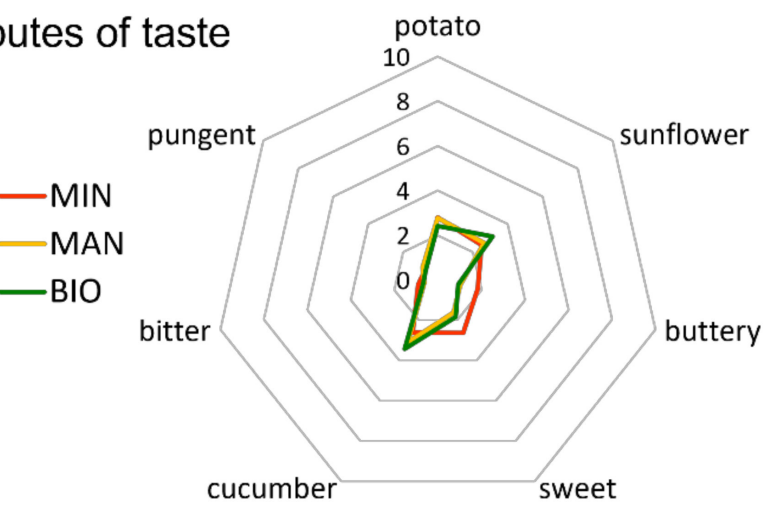

Nimba

Figure 3. Intensity of taste attributes of courgette fruits of Astra Polka and Nimba cultivars grown in horticultural system with commercial organic fertilizer (BIO), manure (MAN), and mineral (MIN) fertilizer. 


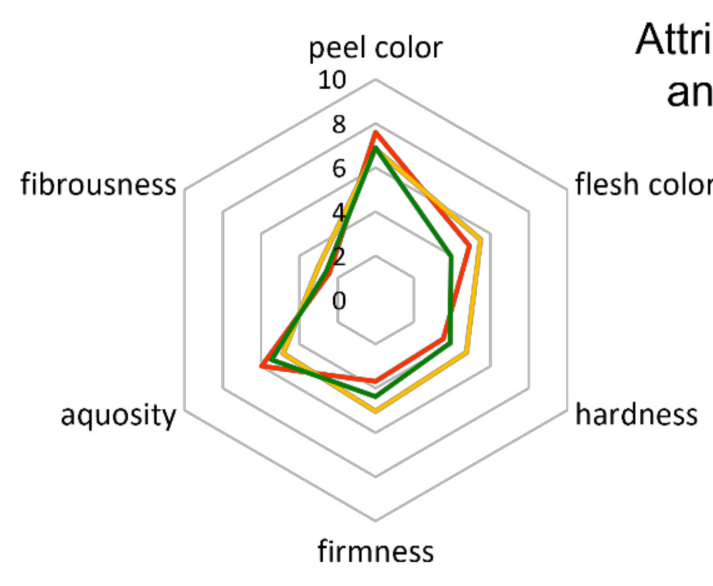

Astra Polka

\section{Attributes of texture and appearance}

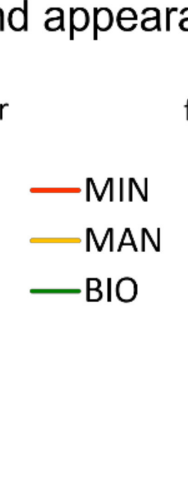

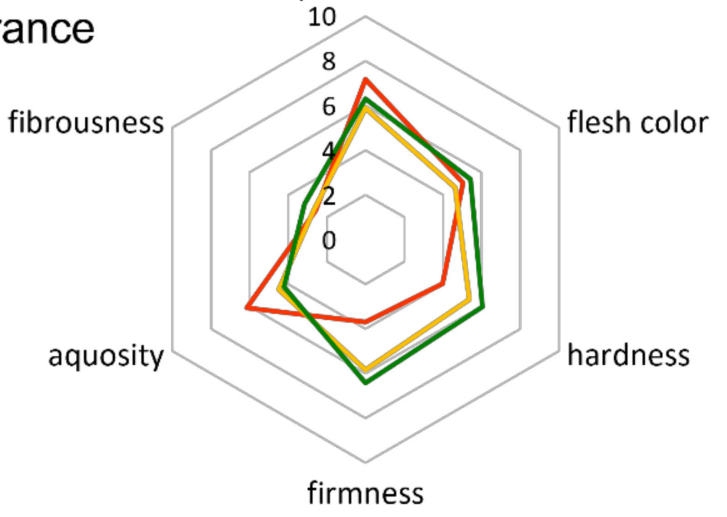

Nimba

Figure 4. Intensity of texture and appearance attributes of courgette fruits of Astra Polka and Nimba cultivars grown in horticultural system with commercial organic fertilizer (BIO), manure (MAN), and mineral (MIN) fertilizer.

Fruits from the organic system based on manure were characterized by the most intensive potato odor, in contrast to the fruits fertilized by the commercial organic fertilizer. The fruits of the two tested cultivars differed significantly in pungent and earthy odor. These odors were perceived as stronger in fruits of the Astra Polka cultivar compared to those of the Nimba cultivar. However, significant interactions between the cultivar and horticultural system were observed in the case of buttery, potato, pungent, and earthy odor (Table 6). In the case of Astra Polka, conventional production resulted in the most intensive potato, pungent, and earthy odor, but the least intensive buttery odor, compared to the two organic systems, while in the case of Nimba, the production system effect was the opposite (Figure S2 in Supplementary Materials). The ANOVA showed no significant impact of any of the two factors on the intensity of sweet and sunflower odor of the courgette fruits (Table 6).

The ANOVA showed no significant impact of the horticultural system on the perceived taste attributes of the courgette fruits. At the same time, fruits of the two studied cultivars differed significantly in the intensity of sweet, cucumber, and pungent taste (Table 7).

Nimba fruits were characterized by significantly more intensive sweet and cucumber taste, but less intensive pungent taste compared to the Astra Polka fruits. However, significant interaction between the cultivar and horticultural system was observed in the case of sweet taste (Table 7). In the case of Nimba, conventional production resulted in the most intensive sweet taste compared to the two organic systems, while in the case of Astra Polka, the intensity of sweet taste was lowest in the fruits coming from the conventional system (Figure 3 and Figure S3 in the Supplementary Materials).

The analysis of variance showed the significant impact of the horticultural production system on attributes such as peel color, hardness, firmness, and aquosity in the courgettes. The conventional courgettes were characterized by the most intensive peel color and aquosity, but at the same time were the least hard and firm compared to the fruits from the two organic systems (Table 8). There was also a trend towards lower overall quality of the conventionally grown fruits (significant only in the case of the Astra Polka cultivar) (Figure S4 in Supplementary Materials). Fruits of the two cultivars differed significantly in their hardness and firmness, with those of the Nimba cultivar being generally characterized by higher values of these two attributes. Other attributes, such as flesh color and fibrousness, did not significantly differ between fruits representing the different cultivars and/or production systems (Table 8).

A principal component analysis (PCA) was also performed to further explore possible differences and similarities in the sensory characteristics of courgette fruits representing different cultivars (Figure 1c) and grown in different horticultural systems (Figure 1d). The PCA ellipses of data on the sensory attributes of the different courgette cultivars 
and different production systems overlap each other, and thus do not show any clear differentiation of the fruit sensory profiles based on the studied experimental factors.

According to the previously published reports, the differences in sensory attributes between organic and conventional crops and foods are not always noticeable [66]. The sensory quality of fruits, vegetables, and grains may depend on their cultivar, weather conditions during cultivation, farming practices, and a number of other factors [67]. TalaveraBianchi et al. (2010) [68], in their study on the relation between the development stage, sensory properties, and volatile content of organically and conventionally grown pac choi, have found that the differences in sensory characteristics among stages of growth were generally more substantial than the differences related to the organic and conventional production. Their results also suggest that the effect of organic production on sensory characteristics may be more evident at early stages of plant development. Rodriguez et al. (2001) [69], in their study on the sensory evaluation of fresh tomatoes from conventional, integrated, and organic production, did not detect any significant differences among the three farming system treatments for any of the tested attributes of flavor and taste. Heeb et al. (2005) [70] reported a significant impact of nitrogen form on the taste of tomatoes, with higher scores of sweetness, acidity, flavor, and overall acceptance of tomatoes grown with the organic or the ammonium-dominated treatments compared with those grown with the nitrate dominated nutrient solution. Raffo et al. (2014) [71] highlighted a significant effect of fertilization treatments (organic vs. conventional) on 10 of 14 measured sensory attributes of Golden Delicious apples. In particular, fertilization treatments significantly affected green, citrus, and floral odors; sweet and sour taste; and overall fruity and green flavors; hardness; and mouthfeel, even though a season to season variability was also marked. Casals et al. (2018) [72] pointed to the significant impact of grafting on the sensory profiles of tomatoes grown in conventional and organic management systems. Paolo et al. (2019) [73] reported that the effect of organic growing on the sensory profiles of dried tomatoes depends strongly on the drying techniques. The authors underlined that organic products are often processed in order to prolong their shelf-life; thus, research efforts on comparing organic and conventional processed foods, and not only raw materials, are of growing relevance in the food science.

The Pearson's correlation analysis of individual taste, odor, appearance, and texture features was also performed in the present study and its results are shown in Figure 5. The pungent odor, pungent taste, and bitter taste were found to be associated with the lower overall quality of fruits. The positive correlations between buttery and sweet odor, buttery and sweet taste, bitter and pungent taste, sunflower taste and odor, and hardness and firmness were also noted (Figure 5). At the same time, a negative association was identified between sunflower odor and peel color of the fruit. According to the literature, sweet taste was found to positively correlate with the overall sensory quality assessment of plants belonging to Cucurbitaceae [42]. In pumpkins, bitter taste was found to be negatively correlated with overall quality assessment, which is in line with the presented results. Furthermore, other authors reported significant differences in the sensory attributes of plants representing different genotypes (cultivars) [74], which was also shown in the present study in the case of a number of tested sensory attributes. 


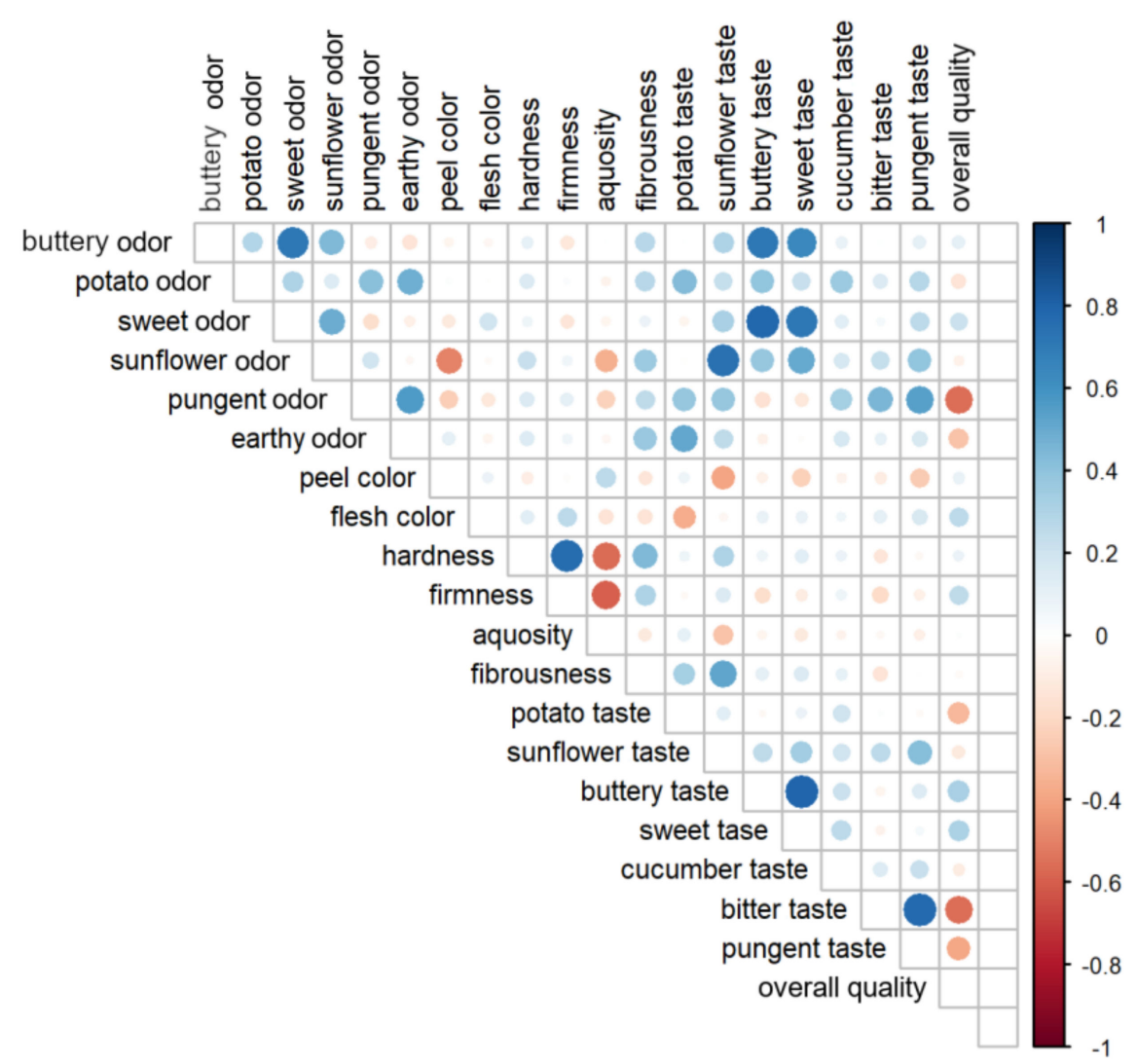

Figure 5. Pearson's correlations between sensory attributes of courgette fruits. Color (red/blue) and the color intensity indicate the direction (positive/negative) and the strength of the correlation, while the size of the circle reflects the statistical significance of the correlation ( $p$-value).

\subsection{The Relationship between the Sensory Features and Chemical Composition of Courgette Fruits}

The redundancy analysis (RDA) was performed to study the relationships between the chemical composition parameters and sensory attributes of courgette fruits (Figure 6). The content of DHA, dry matter, fructose, glucose, and sum of sugars were identified as the main drivers for the tested sensory attributes of the courgette fruits. A positive association was observed between dry matter content and earthy odor, potato odor, pungent odor, potato taste, and pungent taste. This relation was characteristic for conventional fruits of the Astra Polka cultivar. The contents of sugars (sum), fructose, and glucose were found to be positively associated with hardness and firmness, especially for the organic Nimba fruits. The positive relation between DHA content and sensory attributes such as intensity of peel color and aquosity was also observed. The RDA analysis also shows that the organic samples of the Nimba and Astra Polka cultivars are located in different quarters of the biplot, which indicates substantial differences between the organic fruits depending on the cultivar.

The obtained results confirm that the sensory features of the courgette fruits depend on dry matter and sugars content. A strong correlation of sweet taste, determining overall quality assessment, with sugars, dry matter, and carotenoids contents was previously shown in fruits of other varieties of cucurbits $[42,74]$. The relation between individual taste attributes and overall quality assessment depending on the cultivars of cucurbits was also previously shown [42]. A correlation between chlorophyll content and the color and firmness of courgette fruits cut in slices was also reported [63]. 


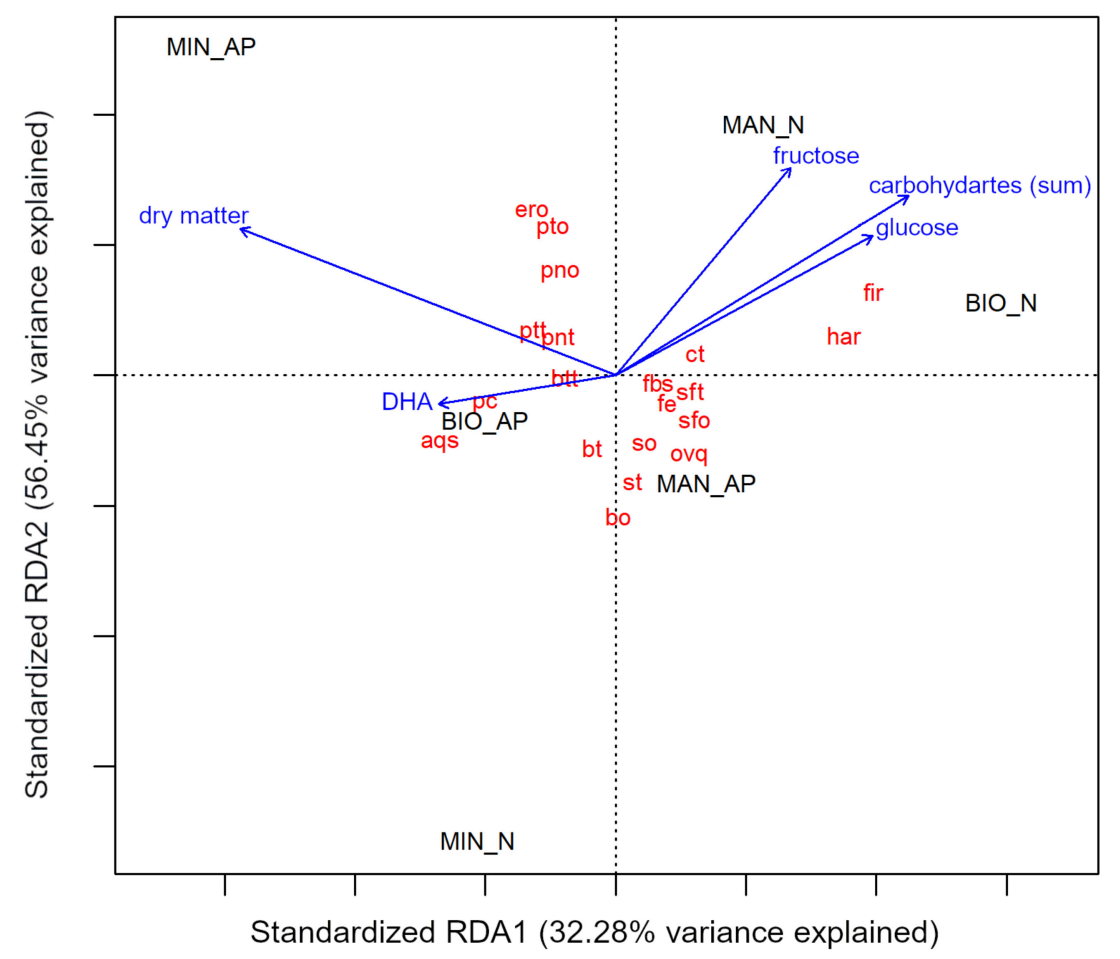

Figure 6. The redundancy analysis (RDA) biplot of chemical composition parameters (sugars, bioactive compounds) and sensory attributes of courgette fruits of Astra Polka (AP) and Nimba (N) cultivars grown in horticultural system with commercial organic fertilizer (BIO), manure (MAN), and mineral (MIN) fertilizer. Bo, buttery odor; pto, potato odor; so, sweet odor; sfo, sunflower odor; pno, pungent odor; ero, earthy odor; ptt, potato taste; sft, sunflower taste; bt, buttery taste; st, sweet taste; ct, cucumber taste; btt, bitter taste; pnt, pungent taste; pc, peel color; fc, flesh color; har, hardness; fir, firmness; aqs, aquosity; fbs, fibrousness; ovq, overall quality.

\subsection{Untargeted Metabolomic Analysis of Organic vs. Conventional Courgette}

The untargeted metabolomic analysis allowed for the detection of around 1000 different metabolic features in the tested courgette fruits. The principal component analysis (PCA) was performed to explore possible differences and/or patterns in the metabolomic profiles of courgette fruits representing different cultivars and grown in different horticultural systems (Figure 7). While data for Astra Polka fruits grown with commercial organic fertilizer were the most scattered, the results representing the other combinations of horticultural systems and cultivars were clearly grouped in the PCA biplot.

The undertaken untargeted analysis allowed for the detection of several metabolic features significantly differentiating the courgette fruits of different cultivars and coming from different horticultural systems. Nimba fruits were characterized by 154 metabolic features significantly differentiating them from Astra Polka fruits. The number of metabolic features significantly differentiating courgette fruits depending on the horticultural system were 119,125 , and 127 for the following comparisons: mineral fertilizer vs. commercial organic fertilizer, mineral fertilizer vs. manure, and manure vs. commercial organic fertilizer, respectively. Information (i.e., retention time) about the metabolic features for which the $\mathrm{m} / \mathrm{z}$ values (the ratio of the atomic mass to the number of elementary ion charges) varied most significantly between the compared fruits are presented in Table S1 in the Supplementary Materials. The difference in the $\mathrm{m} / \mathrm{z}$ values of these metabolic features in the compared courgette fruits is presented as a fold change. The highest fold change was noted for a group of metabolic features differentiating fruits cultivated in the conventional system from fruits grown in the organic system with the use of commercial organic fertilizer (fold change $=243.30, p=0.0000$ ). 


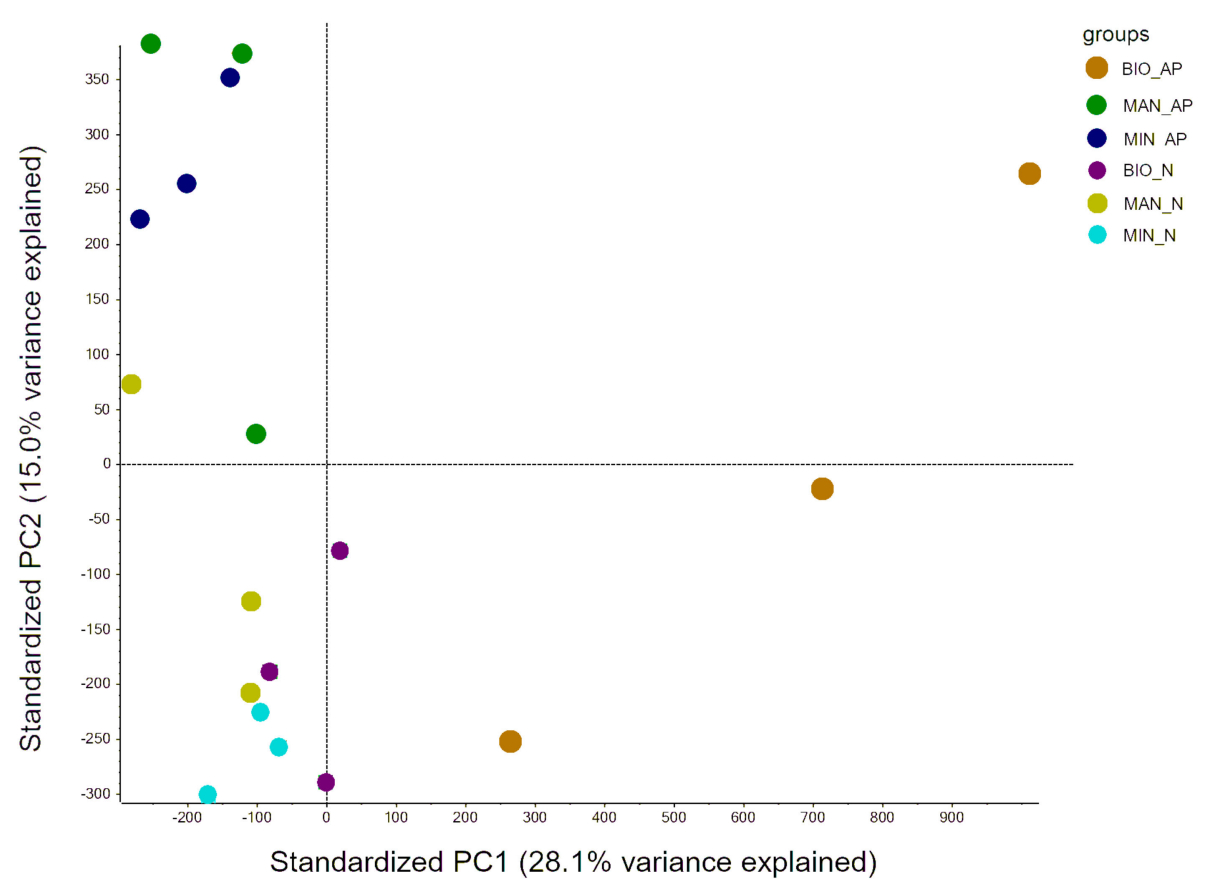

Figure 7. A principal component analysis (PCA) biplot of data on metabolic features of courgette fruits of Astra Polka (AP) and Nimba (N) cultivars grown in horticultural systems with commercial organic fertilizer (BIO), manure (MAN), and mineral (MIN) fertilizer. PC1, the first principal component; PC2, the second principal component.

Metabolomics was previously tested in some studies as a potentially useful tool for the authentication of crops grown in organic production systems [75-78], as well as for recognition of the geographical origins or cultivars of various crops $[79,80]$ and their processing methods $[81,82]$. Omics technologies, including metabolomics, have allowed for the detection of possible nutritional differences between organic and conventional production, although many results remain uncertain [83].

The differences in quantity and type of metabolites are reflected in many food features, including sensory attributes. For example, sensory profiles of melon fruits (Cucumis melo., belonging to the Cucurbitaceae family) depend on metabolites of esters, alcohols, aldehydes, ketones, lactones, terpenoids, and sulfur compounds $[84,85]$. The bitter and spicy taste of dill was reported to be related to the accumulation of several organic acid and amino acid metabolites [86].

\section{Conclusions}

Organic farming aims to provide food produced in accordance with the sustainable use of resources and with the high-quality properties valued by consumers. The presented study focused on qualities such as the health-promoting bioactive compounds, sugars, and sensory attributes of courgette, the vegetable consumed worldwide and performing well in organic horticultural systems. The obtained results did not show a significant effect of the horticultural production system (organic vs. conventional) on the concentration of vitamin C, carotenoids, and chlorophylls in the courgette fruits. However, fruits from both organic systems were generally richer in sugars compared to the conventional fruits. At the same time, organic courgette fruits contained significantly higher amounts of health-promoting plant secondary metabolites-polyphenols, including phenolic acids and flavonoids-compared to the conventional fruits, but only when fertilized with manure. Organic fruits grown with commercial organic multi-component fertilizer were characterized by a lower content of phenolics comparable to that of conventional, minerally fertilized fruits. A similar trend was true for most of the individual phenolic acids and flavonoids identified in the courgette fruits within the study. This result suggests that the organic 
system as such does not guarantee the superior composition of crops, which depends, among other factors, on the type of fertilizer inputs used in the cultivation.

Even though plant genotype is well known to play an important role in determining the quality features of crops, the two courgette cultivars included in this study did not differ significantly in the contents of sugars and the tested bioactive compounds. However, the untargeted metabolomic analysis in this study allowed several metabolic features to be pointed out which significantly differentiated courgette fruits of different cultivars and grown in different horticultural systems. This suggests that metabolomics can be a potentially useful tool for the authentication of crops grown in organic production systems, as well as for the recognition of crops representing different genotypes.

Next to the qualities such as vitamins and other health-promoting compounds, sensory attributes belong to the key factors determining consumers' preferences for foods. Some significant differences in sensory values were identified between the fruits representing the two cultivars or/and coming from the three horticultural systems compared in the present study. In particular, conventional courgettes were characterized by the most intensive peel color and aquosity, but at the same time were the least hard and firm compared to the fruits from the two organic systems. There was also a trend towards higher overall quality of the organically grown fruits.

To the best of our knowledge, this is one of the first reports on the chemical composition, untargeted metabolomics, and sensory characteristics of organic versus conventional courgette fruits.

Supplementary Materials: The following are available online at https:/ /www.mdpi.com/article/10 .3390/foods10102475/s1.

Author Contributions: Conceptualization, K.K. (Klaudia Kopczyńska), D.Ś.-T., E.H., Z.W., K.K. (Katarzyna Kucińska), E.R. and R.K.; data curation, K.K. (Klaudia Kopczyńska), D.Ś.-T., E.H., J.W., M.B., P.G., R.G.-W. and R.K.; formal analysis, K.K. (Klaudia Kopczyńska), E.H., J.W. and G.W.-Z.; funding acquisition, D.Ś.-T.; investigation, K.K. (Klaudia Kopczyńska), D.Ś.-T., E.H., J.W., G.W.-Z., Z.W., A.P., P.S. and R.K.; Methodology, K.K. (Klaudia Kopczyńska), D.Ś.-T., E.H., J.W., G.W.-Z., Z.W., K.K. (Katarzyna Kucińska), A.P., P.S., M.B. and R.K.; supervision, R.K., D.Ś.-T., Z.W. and K.K. (Katarzyna Kucińska); visualization, K.K. (Klaudia Kopczyńska), J.W. and M.B.; writing-original draft, K.K. (Klaudia Kopczyńska), D.Ś.-T. and R.K.; writing-review and editing, K.K. (Klaudia Kopczyńska), D.Ś.-T., E.H., J.W., G.W.-Z., Z.W., K.K. (Katarzyna Kucińska), A.P., P.S., M.B., P.G., R.G.-W., E.R. and R.K. All authors have read and agreed to the published version of the manuscript.

Funding: This research was funded by the Polish Ministry of Science and Higher Education with funds from the Institute of Human Nutrition Sciences and the Institute of Agriculture, Warsaw University of Life Sciences (WULS), for scientific research. The article processing charges were covered with a grant from the Financial Support System for Scientists and Research Teams in the Warsaw University of Life Sciences (awarded in 2020 to D.Ś.-T., grant number 504-02-780400-S00123-99).

Institutional Review Board Statement: Not applicable.

Informed Consent Statement: Not applicable.

Data Availability Statement: Data will be made available upon reasonable request by the corresponding author (Klaudia Kopczyńska).

Conflicts of Interest: The authors declare no conflict of interest. The funders had no role in the design of the study; in the collection, analyses, or interpretation of data; in the writing of the manuscript; or in the decision to publish the results.

\section{References}

1. Lynch, J.; Cain, M.; Frame, D.; Pierrehumbert, R. Agriculture's contribution to climate change and role in mitigation is distinct from predominantly fossil $\mathrm{CO}_{2}$-emitting sectors. Front. Sustain. Food Syst. 2021, 4, 300. [CrossRef]

2. Fritz, S.; See, L.; Carlson, T.; Haklay, M.; Oliver, J.L.; Fraisl, D.; Mondardini, R.; Brocklehurst, M.; Shanley, L.A.; Schade, S.; et al. Citizen science and the United Nations Sustainable Development Goals. Nat. Sustain. 2019, 2, 922-930. [CrossRef]

3. Streimikis, J.; Baležentis, T. Agricultural sustainability assessment framework integrating sustainable development goals and interlinked priorities of environmental, climate and agriculture policies. Sustain. Dev. 2020, 28, 1702-1712. [CrossRef] 
4. Diacono, M.; Persiani, A.; Testani, E.; Montemurro, F. Sustainability of agro-ecological practices in organic horticulture: Yield, energy-use and carbon footprint. Agroecol. Sustain. Food Syst. 2019, 44, 1-21. [CrossRef]

5. Azzurra, A.; Massimiliano, A.; Angela, M. Measuring sustainable food consumption: A case study on organic food. Sustain. Prod. Consum. 2019, 17, 95-107. [CrossRef]

6. Mørk, T.; Bech-Larsen, T.; Grunert, K.G.; Tsalis, G. Determinants of citizen acceptance of environmental policy regulating consumption in public settings: Organic food in public institutions. J. Clean. Prod. 2017, 148, 407-414. [CrossRef]

7. European Commission Council Regulation (EC). No 834/2007 of 28 June 2007 on Organic Production and Labelling of Organic Products and Repealing Regulation (EEC) No 2092/91, OJ L 189, 20.7.2007. 2007, pp. 1-23. Available online: https:/ / eur-lex. europa.eu/legal-content/EN/TXT/?uri=\%20uriserv\%3AOJ.L_.2018.150.01.0001.01.ENG (accessed on 12 September 2021).

8. European Parliament. European Council Regulation (EU) 2018/848 of the European Parliament and of the Council of 30 May 2018 on organic production and labelling of organic products and repealing Council Regulation (EC) No 834/2007. Off. J. Eur. Union 2018, 2018, 150.

9. Smith, L.G.; Kirk, G.J.D.; Jones, P.J.; Williams, A.G. The greenhouse gas impacts of converting food production in England and Wales to organic methods. Nat. Commun. 2019, 10, 4641. [CrossRef]

10. The World of Organic Agriculture Statistics and Emerging Trends 2021, 21st ed.; Willer, H.; Trávníček, J.; Meier, C.; Schlatter, B., Eds.; Research Institute of Organic Agriculture (FiBL) and IFOAM-Organics International: Frick, Switzerland; Bonn, Germany, 2021.

11. Caprile, A.; Rossi, R. 2021 International Year of Fruits and Vegetables. Available online: https://www.fao.org/policy-support/ tools-and-publications/resources-details/es/c/1382166/ (accessed on 20 September 2021).

12. Wang, D.D.; Li, Y.; Bhupathiraju, S.N.; Rosner, B.A.; Sun, Q.; Giovannucci, E.L.; Rimm, E.B.; Manson, J.E.; Willett, W.C.; Stampfer, M.J.; et al. Fruit and vegetable intake and mortality: Results from 2 prospective cohort studies of US men and women and a meta-analysis of 26 cohort studies. Circulation 2021, 143, 1642-1654. [CrossRef] [PubMed]

13. Food and Agriculture Organization of the United Nations (FAO); World Health Organization (WHO). Fruit and Vegetables for Health Initiative; Food and Agriculture Organization of the United Nations: Rome, Italy, 2017.

14. Kalmpourtzidou, A.; Eilander, A.; Talsma, E.F. Global vegetable intake and supply compared to recommendations: A systematic review. Nutrients 2020, 12, 1558. [CrossRef]

15. Godfray, H.C.J.; Aveyard, P.; Garnett, T.; Hall, J.W.; Key, T.J.; Lorimer, J.; Pierrehumbert, R.T.; Scarborough, P.; Springmann, M.; Jebb, S.A. Meat consumption, health, and the environment. Science 2018, 361, 1-8. [CrossRef] [PubMed]

16. Paris, H.S. Germplasm enhancement of Cucurbita pepo (pumpkin, squash, gourd: Cucurbitaceae): Progress and challenges. Euphytica 2016, 208, 415-438. [CrossRef]

17. Salehi, B.; Sharifi-rad, J.; Capanoglu, E.; Adrar, N. Cucurbita Plants: From Farm to Industry. Appl. Sci. 2019, 1010, 3387. [CrossRef]

18. Verdone, M.; Rao, R.; Coppola, M.; Corrado, G. Identification of zucchini varieties in commercial food products by DNA typing. Food Control. 2018, 84, 197-204. [CrossRef]

19. Rouphael, Y.; Kyriacou, M.C.; Petropoulos, S.A.; De Pascale, S.; Colla, G. Improving vegetable quality in controlled environments. Sci. Hortic. 2018, 234, 275-289. [CrossRef]

20. Araujo, J.; Telhado, S. Organic Food: A Comparative Study of the Effect of Tomato Cultivars and Cultivation Conditions on the Physico-Chemical Properties. Foods 2015, 4, 263-270. [CrossRef]

21. Barański, M.; Średnicka-Tober, D.; Volakakis, N.; Seal, C.; Sanderson, R.; Stewart, G.B.; Benbrook, C.; Biavati, B.; Markellou, E.; Giotis, C.; et al. Higher antioxidant and lower cadmium concentrations and lower incidence of pesticide residues in organically grown crops: A systematic literature review and meta-analyses. Br. J. Nutr. 2014, 112, 794-811. [CrossRef]

22. Kazimierczak, R.; Średnicka-Tober, D.; Hallmann, E.; Kopczyńska, K.; Zarzyńska, K. The impact of organic vs. conventional agricultural practices on selected quality features of eight potato cultivars. Agronomy 2019, 9, 799. [CrossRef]

23. Brandt, K.; Srednicka-Tober, D.; Barański, M.; Sanderson, R.; Leifert, C.; Seal, C. Methods for comparing data across differently designed agronomic studies: Examples of different meta-analysis methods used to compare relative composition of plant foods grown using organic or conventional production methods and a protocol for a systemati. J. Agric. Food Chem. 2013, 61, 7173-7180. [CrossRef]

24. Kazimierczak, R.; Siłakiewicz, A.; Hallmann, E.; Srednicka-Tober, D.; Rembiałkowska, E. Chemical composition of selected beetroot juices in relation to beetroot production system and processing technology. Not. Bot. Horti Agrobot. Cluj-Napoca 2016, 44, 491-498. [CrossRef]

25. Srednicka-Tober, D.; Kazimierczak, R.; Ponder, A.; Hallmann, E. Biologically active compounds in selected organic and conventionally produced dried fruits. Foods 2020, 9, 1005. [CrossRef]

26. Hallmann, E.; Marszałek, K.; Lipowski, J.; Jasińska, U.; Kazimierczak, R.; Średnicka-Tober, D.; Rembiałkowska, E. Polyphenols and carotenoids in pickled bell pepper from organic and conventional production. Food Chem. 2019, 278, 254-260. [CrossRef] [PubMed]

27. Bonte, A.; Neuweger, H.; Goesmann, A.; Thonar, C.; Mader, P.; Langenkamper, G.; Niehaus, K. Metabolite profiling on wheat grain to enable a distinction of samples from organic and conventional farming systems. J. Sci. Food Agric. 2014, $2605-2612$. [CrossRef] [PubMed]

28. Lopez-Sanchez, P. Comprehensive metabolomics to evaluate the impact of industrial processing on the phytochemical composition of vegetable purees. Food Chem. 2014, 348-355. [CrossRef] [PubMed] 
29. Zörb, C.; Langenkämper, G.; Betsche, T.; Neehaus, K.; Barsch, A. Metabolite profiling of wheat grains (Triticum aestivum L.) from organic and conventional agriculture. J. Agric. Food Chem. 2006, 54, 8301-8306. [CrossRef] [PubMed]

30. Vallverdú-Queralt, A.; Medina-Remón, A.; Casals-Ribes, I.; Amat, M.; Lamuela-Raventós, R.M. A metabolomic approach differentiates between conventional and organic ketchups. J. Agric. Food Chem. 2011, 59, 11703-11710. [CrossRef] [PubMed]

31. Caprioli, G.; Logrippo, S.; Cahill, M.G.; James, K.J. High-performance liquid chromatography LTQ-Orbitrap mass spectrometry method for tomatidine and non-target metabolites quantification in organic and normal tomatoes. Int. J. Food Sci. Nutr. 2014, 65, 942-947. [CrossRef] [PubMed]

32. Średnicka-Tober, D.; Ponder, A.; Hallmann, E.; Głowacka, A.; Rozpara, E. The Profile and Content of Polyphenols and Carotenoids in Local and Commercial Sweet Cherry Fruits (Prunus avium L.) and Their Antioxidant Activity In Vitro. Antioxidants 2019, 8, 534. [CrossRef]

33. The Polish Committe for Standardization. Polish Norm PN-EN 12145 Fruits and Vegetable Juices-Determination of Dry MatterGravimetric Method; The Polish Committee for Standardization: Warsaw, Poland, 2001.

34. Ma, Y.Q.; Ye, X.Q.; Fang, Z.X.; Chen, J.C.; Xu, G.H.; Liu, D.H. Phenolic compounds and antioxidant activity of extracts from ultrasonic treatment of satsuma mandarin (Citrus unshiu Marc.) peels. J. Agric. Food Chem. 2008, 56, 5682-5690. [CrossRef]

35. Nishiyama, I.; Fukuda, T.; Oota, T. Genotypic Differences in Chlorophyll, Lutein, and b-Carotene contents in the Fruits of Actinidia Species. J. Agric. Food Chem. 2005, 6403-6407. [CrossRef]

36. Kopczyńska, K.; Kazimierczak, R.; Średnicka-Tober, D.; Barański, M.; Wyszyński, Z.; Kucińska, K.; Perzanowska, A.; Szacki, P.; Rembiałkowska, E.; Hallmann, E. The Profile of Selected Antioxidants in Two Courgette Varieties from Organic and Conventional Production. Antioxidants 2020, 9, 404. [CrossRef] [PubMed]

37. Ponder, A.; Hallmann, E. The nutritional value and vitamin C content of different raspberry cultivars from organic and conventional production. J. Food Compos. Anal. 2020, 87, 103429. [CrossRef]

38. International Organization for Standarization. ISO 13299 Sensory Analysis_Methodology_General Quidance for Establishing a Sensory Profile; International Organization for Standarization: Geneva, Switzerland, 2016.

39. Polish Standard Committee, International Organization for Standarization. Sensory Analysis, general guidance for theselection, training and monitoring of accessors. In Polish Standard PN-EN ISO 8586-03; Polish Standard Committee, International Organization for Standarization: Geneva, Switzerland, 2014.

40. R Core Team. An Introduction to R.; R Foundation for Statistical Computing: Vienna, Austria, 2019.

41. Martínez-Valdivieso, D.; Gómez, P.; Font, R.; Alonso-Moraga, Á.; Río-Celestino, M. Del Physical and chemical characterization in fruit from 22 summer squash (Cucurbita pepo L.) cultivars. LWT Food Sci. Technol. 2015, 64, 1225-1233. [CrossRef]

42. Pevicharova, G.; Velkov, N. Sensory, chemical and morphological characterization of Cucurbita maxima and Cucurbita moschata genotypes from different geographical origins. Genetika 2017, 49, 193-202. [CrossRef]

43. Martínez-Valdivieso, D.; Gómez, P.; Font, R.; Río-Celestino, M. Del Mineral composition and potential nutritional contribution of 34 genotypes from different summer squash morphotypes. Eur. Food Res. Technol. 2014, 240, 71-81. [CrossRef]

44. Palma, F.; Carvajal, F.; Lluch, C.; Jamilena, M.; Garrido, D. Changes in carbohydrate content in zucchini fruit (Cucurbita pepo L.) under low temperature stress. Plant. Sci. 2014, 217-218, 78-86. [CrossRef]

45. Uddain, J.; Islam Tripti, S.; Shah Jahan, M.; Sultana, N.; Rahman, M.J.; Subramaniam, S. Changes of Morphological and Biochemical Properties in Organically Grown Zucchini Squash (Cucurbita pepo L.). HortScience 2019, 54, 1485-1491. [CrossRef]

46. Armesto, J.; Rocchetti, G.; Senizza, B.; Pateiro, M.; Barba, F.J.; Domínguez, R.; Lucini, L.; Lorenzo, J.M. Nutritional characterization of Butternut squash (Cucurbita moschata D.): Effect of variety (Ariel vs. Pluto) and farming type (conventional vs. organic). Food Res. Int. 2020, 132, 109052. [CrossRef]

47. Oloyede, F.M.; Agbaje, G.O.; Obuotor, E.M.; Obisesan, I.O. Nutritional and antioxidant profiles of pumpkin (Cucurbita pepo Linn.) immature and mature fruits as influenced by NPK fertilizer. Food Chem. 2012, 135, 460-463. [CrossRef]

48. Kopta, T.; Híc, P.; Šlosár, M.; Pokluda, R. Quality changes in organic and conventional Hokkaido pumpkin (Cucurbita maxima Duch.) during storage. Biol. Agric. Hortic. 2018, 34, 1-9. [CrossRef]

49. Iswaldi, I.; Gómez-Caravaca, A.M.; Lozano-Sánchez, J.; Arráez-Román, D.; Segura-Carretero, A.; Fernández-Gutiérrez, A. Profiling of phenolic and other polar compounds in zucchini (Cucurbita pepo L.) by reverse-phase high-performance liquid chromatography coupled to quadrupole time-of-flight mass spectrometry. Food Res. Int. 2013, 50, 77-84. [CrossRef]

50. Kopczyńska, K.; Kazimierczak, R.; Średnicka-Tober, D.; Szafirowska, A.; Barański, M.; Rembiałkowska, E.; Hallmann, E. The Effect of Organic vs. Conventional Cropping Systems on the Yield and Chemical Composition of Three Courgette Cultivars. Agronomy 2020, 10, 1341. [CrossRef]

51. Rempelos, L.; Almuayrifi, A.M.; Baranski, M.; Tetard-Jones, C.; Eyre, M.; Shotton, P.; Cakmak, I.; Ozturk, L.; Cooper, J.; Volakakis, N.; et al. Effects of agronomic management and climate on leaf phenolic profiles, disease severity, and grain yield in organic and conventional wheat production systems. J. Agric. Food Chem. 2018, 66, 10369-10379. [CrossRef] [PubMed]

52. Rempelos, L.; Almuayrifi, M.S.B.; Baranski, M.; Tetard-Jones, C.; Barkla, B.; Cakmak, I.; Ozturk, L.; Cooper, J.; Volakakis, N.; Hall, G.; et al. The effect of agronomic factors on crop health and performance of winter wheat varieties bred for the conventional and the low input farming sector. F. Crop. Res. 2020, 254, 107822. [CrossRef]

53. Hasanaliyeva, G.; Chatzidimitrou, E.; Wang, J.; Baranski, M.; Volakakis, N.; Pakos, P.; Seal, C.; Rosa, E.A.S.; Markellou, E.; Iversen, P.O.; et al. Effect of organic and conventional production methods on fruit yield and nutritional quality parameters in three traditional cretan grape varieties: Results from a farm survey. Foods 2021, 10, 476. [CrossRef] 
54. Hasanaliyeva, G.; Chatzidimitrou, E.; Wang, J.; Baranski, M.; Volakakis, N.; Seal, C.; Rosa, E.A.S.; Iversen, P.O.; Vigar, V.; Barkla, B.; et al. Effects of production region, production systems and grape type/variety on nutritional quality parameters of table grapes; results from a UK retail survey. Foods 2020, 9, 1874. [CrossRef]

55. Margaritopoulou, T.; Toufexi, E.; Kizis, D.; Balayiannis, G.; Anagnostopoulos, C.; Theocharis, A.; Rempelos, L.; Troyanos, Y.; Leifert, C.; Markellou, E. Reynoutria sachalinensis extract elicits SA-dependent defense responses in courgette genotypes against powdery mildew caused by Podosphaera xanthii. Sci. Rep. 2020, 10, 3354. [CrossRef]

56. Wegener, C.; Jansen, G.; Jurgens, H.-U. Influence of drought and wounding stress on soluble phenols and proteins in potato tubers. Sustain. Agric. Res. 2014, 3. [CrossRef]

57. Salehi, B.; Capanoglu, E.; Adrar, N.; Catalkaya, G.; Shaheen, S.; Jaffer, M.; Giri, L.; Suyal, R.; Jugran, A.K.; Calina, D.; et al. Cucurbits plants: A key emphasis to its pharmacological potential. Molecules 2019, 24, 1854. [CrossRef]

58. Hamissou, M.; Smith, A.C.; Carter, R.E.; Triplett, J.K. Antioxidative properties of bitter gourd (Momordica charantia) and zucchini (Cucurbita pepo). Emirates J. Food Agric. 2013, 25, 641-647. [CrossRef]

59. Kulczynski, B.; Gramza-Michałowska, A. The profile of secondary metabolites and other bioactive compounds in cucurbita Pepo L. And cucurbita moschata pumpkin cultivars. Molecules 2019, 24, 2945. [CrossRef]

60. Bonina-Noseworthy, J.; Loy, J.B.; Curran-Celentano, J.; Sideman, R.; Kopsell, D.A. Carotenoid concentration and composition in winter squash: Variability associated with different cultigens, harvest maturities, and storage times. HortScience 2016, 51, 472-480. [CrossRef]

61. Popa, M.E.; Mitelut, A.C.; Popa, E.E.; Stan, A.; Popa, V.I. Organic foods contribution to nutritional quality and value. Trends Food Sci. Technol. 2018, 84, 15-18. [CrossRef]

62. Nowicka, P.; Wojdyło, A. Anti-Hyperglycemic and Anticholinergic Effects of Natural Antioxidant Contents in Edible Flowers. Antioxidants 2019, 8, 308. [CrossRef]

63. Blanco-Diaz, M.T.; Perez-Vicente, A.; Font, R. Quality of Fresh Cut Zucchini as Affected by Cultivar, Maturity at Processing and Packaging. Packag. Technol. Sci. 2016, 29, 365-382. [CrossRef]

64. Neocleous, D.; Savvas, D. Modelling Ca2+ accumulation in soilless zucchini crops: Physiological and agronomical responses. Agric. Water Manag. 2018, 203, 197-206. [CrossRef]

65. Fekete, D.; Balázs, G.; Bőhm, V.; Várvölgyi, E.; Kappel, N. Sensory evaluation and electronic tongue for sensing grafted and non-grafted watermelon taste attributes. Acta Aliment. 2018, 47, 487-494. [CrossRef]

66. Bourn, D.; Prescott, J. A comparison of the nutritional value, sensory qualities, and food safety of organically and conventionally produced foods. Crit. Rev. Food Sci. Nutr. 2002, 42, 1-34. [CrossRef] [PubMed]

67. Mditshwa, A.; Magwaza, L.S.; Tesfay, S.Z.; Mbili, N. Postharvest quality and composition of organically and conventionally produced fruits: A review. Sci. Hortic. 2017, 216, 148-159. [CrossRef]

68. Talavera-Bianchi, M.; Adhikari, K.; Chambers, E.; Carey, E.E.; Chambers, D.H. Relation between developmental stage, sensory properties, and volatile content of organically and conventionally grown pac choi (Brassica rapa var. Mei Qing Choi). J. Food Sci. 2010, 75, S173-S181. [CrossRef] [PubMed]

69. Rodríguez, A.; Ballesteros, R.; Ciruelos, A.; Barreiros, J.M.; Latorre, A. Sensory evaluation of fresh tomato from conventional, integrated, and organic production. Acta Hortic. 2001, 542, 277-282. [CrossRef]

70. Heeb, A.; Lundegårdh, B.; Ericsson, T.; Savage, G.P. Nitrogen form affects yield and taste of tomatoes. J. Sci. Food Agric. 2005, 85, 1405-1414. [CrossRef]

71. Raffo, A.; Baiamonte, I.; Bucci, R.; D’Aloise, A.; Kelderer, M.; Matteazzi, A.; Moneta, E.; Nardo, N.; Paoletti, F.; Peparaio, M. Effects of different organic and conventional fertilisers on flavour related quality attributes of cv. Golden Delicious apples. LWT Food Sci. Technol. 2014, 59, 964-972. [CrossRef]

72. Casals, J.; Rull, A.; Bernal, M.; González, R.; Romero Del Castillo, R.; Simó, J. Impact of grafting on sensory profile of tomato landraces in conventional and organic management systems. Hortic. Environ. Biotechnol. 2018, 59. [CrossRef]

73. Paolo, D.; Bianchi, G.; Morelli, C.F.; Speranza, G.; Campanelli, G.; Kidmose, U.; Lo Scalzo, R. Impact of drying techniques, seasonal variation and organic growing on flavor compounds profiles in two Italian tomato varieties. Food Chem. 2019, 298, 125062. [CrossRef]

74. Gajewski, M.; Radzanowska, J.; Danilcenko, H.; Jariene, E. Quality of Pumpkin Cultivars in Relation to Sensory Characteristics. Not. Bot. Horti Agrobot. Cluj-Napoca 2008, 36, 73-79. [CrossRef]

75. Ordoudi, S.A.; Cagliani, L.R.; Lalou, S.; Naziri, E.; Tsimidou, M.Z.; Consonni, R. 1H NMR-based metabolomics of saffron reveals markers for its quality deterioration. Food Res. Int. 2015, 70, 1-6. [CrossRef]

76. Consonni, R.; Polla, D.; Cagliani, L.R. Organic and conventional coffee differentiation by NMR spectroscopy. Food Control. 2018, 94, 284-288. [CrossRef]

77. Xiao, R.; Ma, Y.; Zhang, D.; Qian, L. Discrimination of conventional and organic rice using untargeted LC-MS-based metabolomics. J. Cereal Sci. 2018, 82, 73-81. [CrossRef]

78. Cubero-Leon, E.; De Rudder, O.; Maquet, A. Metabolomics for organic food authentication: Results from a long-term field study in carrots. Food Chem. 2018, 239, 760-770. [CrossRef] [PubMed]

79. Toci, A.T.; de Moura Ribeiro, M.V.; de Toledo, P.R.A.B.; Boralle, N.; Pezza, H.R.; Pezza, L. Fingerprint and authenticity roasted coffees by 1H-NMR: The Brazilian coffee case. Food Sci. Biotechnol. 2018, 27, 19-26. [CrossRef] [PubMed] 
80. Ghisoni, S.; Lucini, L.; Angilletta, F.; Rocchetti, G.; Farinelli, D.; Tombesi, S.; Trevisan, M. Discrimination of extra-virgin-olive oils from different cultivars and geographical origins by untargeted metabolomics. Food Res. Int. 2019, 121, 746-753. [CrossRef]

81. Lin, X.; Gao, H.; Ding, Z.; Zhan, R.; Zhou, Z.; Ming, J. Comparative Metabolic Profiling in Pulp and Peel of Green and Red Pitayas (Hylocereus polyrhizus and Hylocereus undatus) Reveals Potential Valorization in the Pharmaceutical and Food Industries. Biomed. Res. Int. 2021, 2021, 1-12. [CrossRef]

82. Xu, X.; Bi, S.; Lao, F.; Chen, F.; Liao, X.; Wu, J. Comprehensive investigation on volatile and non-volatile metabolites in broccoli juices fermented by animal- and plant-derived Pediococcus pentosaceus. Food Chem. 2021, 341, 128118. [CrossRef]

83. Vallverdú-Queralt, A.; Lamuela-Raventós, R.M. Foodomics: A new tool to differentiate between organic and conventional foods. Electrophoresis 2016, 37, 1784-1794. [CrossRef]

84. Pavagadhi, S.; Swarup, S. Metabolomics for evaluating flavor-associated metabolites in plant-based products. Metabolites 2020, 10, 197. [CrossRef]

85. Jordán, M.J.; Shaw, P.E.; Goodner, K.L. Volatile components in aqueous essence and fresh fruit of Cucumis melo cv. Athena (muskmelon) by GC-MS and GC-O. J. Agric. Food Chem. 2001, 49, 5929-5933. [CrossRef] [PubMed]

86. Castro-Alves, V.; Kalbina, I.; Nilsen, A.; Aronsson, M.; Rosenqvist, E.; Jansen, M.A.K.; Qian, M.; Öström, Å.; Hyötyläinen, T.; Strid, Å. Integration of non-target metabolomics and sensory analysis unravels vegetable plant metabolite signatures associated with sensory quality: A case study using dill (Anethum graveolens). Food Chem. 2021, 344, 128714. [CrossRef] 